\title{
Merging scleractinian genera: the overwhelming genetic similarity between solitary Desmophyllum and colonial Lophelia
}

\author{
Anna Maria Addamo', Agostina Vertino ${ }^{2,3}$, Jaroslaw Stolarski ${ }^{4}$, Ricardo García-Jiménez ${ }^{1}$, Marco Taviani, ${ }^{5,6,7}$ \\ and Annie Machordom ${ }^{1 *}$
}

\begin{abstract}
Background: In recent years, several types of molecular markers and new microscale skeletal characters have shown potential as powerful tools for phylogenetic reconstructions and higher-level taxonomy of scleractinian corals. Nonetheless, discrimination of closely related taxa is still highly controversial in scleractinian coral research. Here we used newly sequenced complete mitochondrial genomes and 30 microsatellites to define the genetic divergence between two closely related azooxanthellate taxa of the family Caryophylliidae: solitary Desmophyllum dianthus and colonial Lophelia pertusa.
\end{abstract}

Results: In the mitochondrial control region, an astonishing $99.8 \%$ of nucleotides between L. pertusa and D. dianthus were identical. Variability of the mitochondrial genomes of the two species is represented by only 12 non-synonymous out of 19 total nucleotide substitutions. Microsatellite sequence (37 loci) analysis of L. pertusa and D. dianthus showed genetic similarity is about $97 \%$. Our results also indicated that L. pertusa and D. dianthus show high skeletal plasticity in corallum shape and similarity in skeletal ontogeny, micromorphological (septal and wall granulations) and microstructural characters (arrangement of rapid accretion deposits, thickening deposits).

Conclusions: Molecularly and morphologically, the solitary Desmophyllum and the dendroid Lophelia appear to be significantly more similar to each other than other unambiguous coral genera analysed to date. This consequently leads to ascribe both taxa under the generic name Desmophyllum (priority by date of publication). Findings of this study demonstrate that coloniality may not be a robust taxonomic character in scleractinian corals.

Keywords: Mitochondrial genome, Microsatellites, Genetic divergence, Skeletal plasticity, Desmophyllum dianthus, Lophelia pertusa

\section{Background}

Mitogenomics, or the analysis of complete mitochondrial genomic data sets, is a powerful tool used in a wide range of organisms to improve phylogenetic estimations, reconstruct robust phylogenies and resolve long-standing phylogenetic uncertainties [1-6]. Scleractinian mitochondrial genomes are estimated to be evolving 10-20 times slower than vertebrate ones, and five times slower than scleractinian nuclear genomes $[7,8]$, suggesting their limited application for species-level phylogenetics and population

\footnotetext{
* Correspondence: annie@mncn.csic.es

'Departamento de Biodiversidad y Biología Evolutiva, Museo Nacional de Ciencias Naturales (MNCN-CSIC), José Gutiérrez Abascal 2, 28006 Madrid, Spain

Full list of author information is available at the end of the article
}

genetics $[9,10]$. Nevertheless, they were reported as a useful tool for detecting population variability and structure $[11,12]$. Furthermore, mitochondrial genome rearrangements occur relatively rarely and have been useful in resolving evolutionary relationships of closely related species, particularly in Scleractinia [13-19].

Desmophyllum dianthus (Esper, 1794) and Lophelia pertusa (Linneus, 1758) are azooxanthellate scleractinian corals living in cold waters worldwide, with the exception of the polar seas [20-22]. Both species belong to the polyphyletic family Caryophylliidae that is represented by several molecular clusters within Robusta [23, 24], one of three major molecular clades of scleractinian corals [25]. According to recent studies the family 
Caryophylliidae includes, besides Desmophyllum and Lophelia, numerous (ca. 70) modern species of nominal genera as Caryophyllia, Crispatotrochus Tenison-Woods, 1878, Dasmosmilia Pourtales, 1880, Pourtalosmilia Duncan, 1884, and Stenocyathus Pourtalès, 1868 (traditionally classified as representative of Guyniidae, see also [26]).

While $D$. dianthus is one out of three existing species (D. quinarium Tenison-Woods, 1879 and D. striatum Cairns, 1979) of the genus Desmophyllum Ehrenberg, 1834, L. pertusa is monotypic for the genus Lophelia Milne Edwards \& Haime, 1849.

Desmophyllum dianthus is a solitary but gregarious scleractinian species that actively contributes to the accretion of cold-water coral build-ups. Planulae of this species preferentially settle on parental skeleton, producing "branching" structures that, in some cases, can be mistaken as irregular colonies (Fig. 1a). The skeleton of this species is extremely variable, from very thin-walled to massive and from subcylindrical to trochoid and greatly flared (Fig. 1c, f, g, [20, 27-30]). Lophelia pertusa is a colonial species, forming bush-like colonies that can exceed one metre in diameter. It is the most common azooxanthellate frame-building scleractinian and the main component of the densest and most extensive cold-water coral bioconstructions known thus far (e.g. Norwegian continental shelf $[22,31])$. Although less irregular than $D$. dianthus, the skeleton of $L$. pertusa is quite variable both in colonial pattern and calicular size and shape (Fig. 1a, b, d, e, [20, 27-29]). Both species typically occur in deep-water environments where they often share the same habitat, as documented in modern and Pleistocene settings in the Atlantic Ocean and Mediterranean Sea [e.g., 20, 28, 31-36]. However, one of the two species can dominate a distinct ecological niche within the same area (e.g. "solitary coral facies" $[35,36]$ ) or in different areas of the same basin [37-39]. Occasionally, only one of the two species is present in some environments: e.g., $D$. dianthus forms the dense shallow-water bioconstructions in the Chilean fjords [40, 41], whereas L. pertusa dominates the Norwegian "Cold-Water Coral (CWC) reefs" [42, 43].

Though identified as two distinct genera, morphological and genetic similarities have been previously reported between Desmophyllum and Lophelia [20, 24, 44] and references therein [45], suggesting an ambiguous taxonomic status that requires confirmation. The main objective of this study is to establish a genetic fingerprint and clarify the phylogenetic relationship between $D$. dianthus and L. pertusa. New data consisting of complete mitochondrial genomes and other molecular markers,
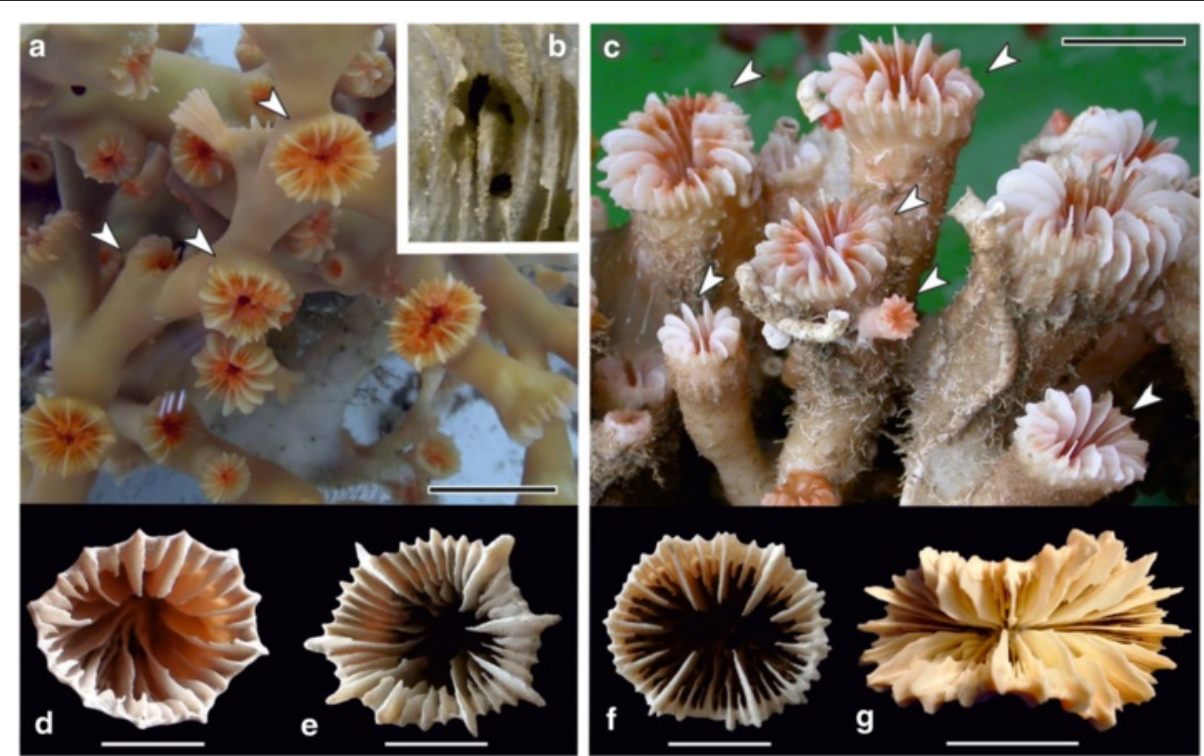

Fig. 1 Colony and corallites of Lophelia pertusa and coralla of Desmophyllum dianthus. a. Branches of a live colony (multiple connected polyps) of L. pertusa (Moira Mounds, Porcupine Seabight, NE Atlantic; UniMiB-MM15). White arrows indicate examples of interconnected single polyps/corallites. b. Detail of the inner wall of a corallite of $L$. pertusa; note the holes that internally connect the soft tissues of two corallites of the same colony; these holes are missing in the wall of aggregated coralla of D. dianthus. c. Live aggregation of several solitary coralla of D. dianthus (Bari Canyon, Adriatic Sea, Mediterranean, dive 108, METEOR 70-1 cruise; sample held at Senckenberg am Meer, Germany). The skeletons of the coralla are secondarily fused, there is no connection between polyps (orange); each polyp/corallum (white arrows) results from a distinct larva settled on the parental skeleton. $\mathbf{d}$-e. Calicular views of two corallites of Lophelia; at comparable sizes septa show different distribution pattern and size. f-g. Calicular views of two coralla of Desmophyllum dianthus showing high intraspecific morphological variability; d. UniMiB-SGC4, South Gulf of Cadiz; e. UniMiB-SML5, Ionian Sea, Mediterranean; f. UniMiB-SML8, Ionian Sea, Mediterranean; g. USNM 92612, Sagami Bay, Japan. Scale bars: a,c,g. $2 \mathrm{~cm}$, b. $2 \mathrm{~mm}$, d-f. $1 \mathrm{~cm}$ 
including previously analysed protein-coding and noncoding genes, were used to provide a robust molecular framework for reaching clear interpretations. We also provide further ontogenetic, microstructural, macro- and micromorphological evidence of the high degree of skeletal similarity between $L$. pertusa and $D$. dianthus.

\section{Results}

\section{Genetic analysis}

The mitochondrial genome of $D$. dianthus, with a length of between 16,229 and 16,310 base pairs (bp), had a nucleotide composition with a GC content of $35 \%$, similar to other corals $[16,46]$. The mitochondrial genome rearrangement of $D$. dianthus was the same as described for L. pertusa [15]: the mitogenome contained 13 protein-coding genes, 2 transfer RNA genes, 2 ribosomal RNA genes, and a group I intron, which interrupted the $n d 5$ gene. This group consisted of one ribosomal ( $r n s$ ) and seven protein-coding genes (Fig. 2). Nearly all protein- coding genes had methionine (ATG) as the translation initiation codon (except $c o b$ and nad2, which had TAT and TTA, respectively), and TAA or TAG as the stop codon. The two largest non-coding regions were between the $n a d 5$ and $c o b$ genes, consisting of the putative control region [15], and the nad6 and trn $W$ genes. The putative control region was responsible for the mitogenome length variation observed at both inter- and intraspecific levels: small insertions and deletions (INDELs) ranging from $72 \mathrm{bp}$ to $150 \mathrm{bp}$ in length were detected in L. pertusa (16,150 bp), and the Italian $(16,229 \mathrm{bp})$ and Chilean (16,310 bp) specimens of $D$. dianthus (see Additional file 1.1).

Comparison of the two $D$. dianthus and three $L$. pertusa mitogenomes (excluding the putative control region) showed that genomic variability was represented by 86 nucleotide substitutions, of which 22 were nonsynonymous (Table 1 , see Additional file $1.2 \mathrm{a}$ and $1.2 \mathrm{~b})$. Intraspecific variability between $D$. dianthus

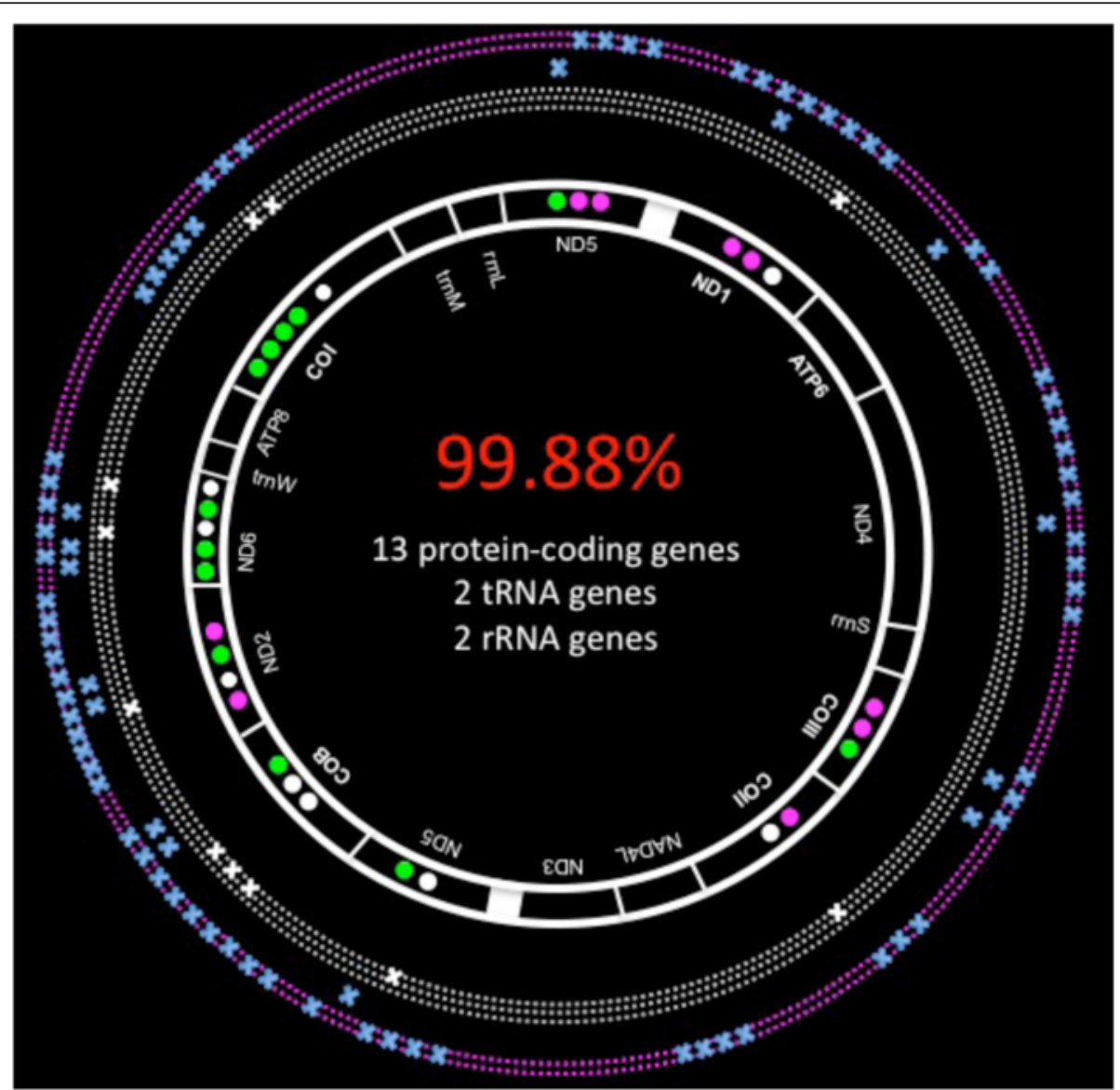

Fig. 2 Mitochondrial sequences, gene arrangement and comparison between two Desmophyllum dianthus (from Mediterranean Sea and Chilean fjord, circle of purple dots) and three Lophelia pertusa (from Mediterranean Sea and Norwegian fjords, circle of white dots) specimens. The mitochondrial genomes of D. dianthus and L. pertusa show $99.88 \%$ of genetic similarity. Nucleotide substitutions obtained in this study are indicated at the intra- and interspecific levels (blue cross). Intraspecific variability of the mitochondrial genome of L. pertusa (white cross) is attributed to the study of Flot et al. (2013) [50]. Non-synonymous substitutions found at interspecific (green point) and intraspecific levels (purple point for D. dianthus; white point for L. pertusa) are represented for each gene from which they were obtained 
individuals from the Mediterranean Sea and Chilean fjord was based on 9 non-synonymous substitutions of 67 mutations, with $99.58 \%$ genetic similarity. Except for the INDELs in the putative control region, astonishing genetic similarity was found between $L$. pertusa and $D$. dianthus: only 12 substitutions out of 19 were observed over 13 coding genes; the remaining $99.88 \%$ nucleotides were identical.

The $\mathrm{dN} / \mathrm{dS}$ values obtained from pairwise comparisons between the mitochondrial protein-coding regions from individuals of both species ranged from 0.13 to 0.30 . Higher substitution ratios, due to mathematical artefacts (e.g. when only one non-synonymous substitution occurs), were found between specimens of $L$. pertusa (Table 2).

Based on the estimation of uncorrected $p$-distances among different scleractinian families and genera, genetic divergence ranged from 4 to $8 \%$ between genera and 0.2 to $1 \%$ between species (see Additional file 2). The genetic distance between Lophelia and Desmophyllum genera was estimated to be $0.8 \%$, the same value obtained when the two $D$. dianthus individuals were compared.

Estimations for the putative control region were performed separately. Within this region, pairwise comparisons between $9 \mathrm{D}$. dianthus and $5 \mathrm{~L}$. pertusa individuals showed overlapping genetic distance ranges, from 9 to $14 \%$ between genera and 0.3 to $14 \%$ at the intraspecific level (Table 3).

Microsatellite sequence analysis showed that 30 microsatellite markers, developed for $D$. dianthus [47], successfully genotyped $L$. pertusa with clear peak profiles. In addition, $L$. pertusa individuals from the Mediterranean Sea and North Atlantic Ocean presented the same allele size range as $D$. dianthus (see Additional file 1.3, Additional file 3). Moreover, average microsatellite sequence identities between $L$. pertusa and $D$. dianthus were about $97 \%$ similar, based on multiple BLAST alignments for 1368 separate pairwise comparisons.

\section{Skeletal analysis}

The morphological analysis carried out in this study confirmed the extreme variability of the coralla of $D$. dianthus (solitary scleractinian; Fig. 1c, f, g, Fig. 1 in Addamo et al. [30]), higher than the variability of $L$. pertusa's corallites (colonial scleractinian; Fig. 1a, b, d, e), consistent with the findings of previous studies of modern and Pleistocene samples [e.g., 20, 28, 30,48]. The initial growth stages of the two taxa were hardly distinguishable, as it has been observed with other closely related caryophylliids [e.g. 49]. Coralla of larger juvenile $D$. dianthus (from 4 to $16 \mathrm{~mm}$ ) were still very similar to $L$. pertusa corallites; however, at equal GCDs, the number of septa was higher in $D$. dianthus (see Additional file 1.4, Additional file 4;
Fig. 1e, f) as confirmed by the Student's two-tailed $t$-test (t-value is $12.107, p$-value is $<0.00001$ ).

The main distinctive characters of the adult stages of $L$. pertusa and $D$. dianthus were a size maximum (Table 4) and growth form, colonial in the former species and solitary in the latter. Although some mass occurrences of $D$. dianthus looked like colonies (Fig. 1c), they were always formed by aggregation of coralla and not by budding as in L. pertusa. Indeed, individual polyps of aggregated $D$. dianthus were never internally connected, whereas the polyps of $L$. pertusa were always connected both externally and internally (Fig. 1b), at least during the early growth stage. Through growth, L. pertusa polyps can seal the connecting skeletal holes and, in some cases, occupy only the distal-most portion of the corallites, thus behaving as independent solitary scleractinians (e.g. Figure four a in [29]).

Other macroscopic skeletal features were extremely variable between specimens of the same taxon and even changed within the same specimen (e.g. L. pertusa calice shape in Fig. 1a). Therefore, they could not be considered diagnostic taxonomic characters. Also, the skeletal microarchitecture of the two taxa was highly variable. The size and shape of both septal and outer thecal granulations tended to change with ontogenetic development and specimen size. In both $D$. dianthus and $L$. pertusa, granules were typically denser and larger (and often more rounded) in the proximal portions and more dispersed and smaller (and often more spinose) in distal portions (Fig. 3). This was particularly evident in large-sized specimens of $D$. dianthus in which portions of the distal corallum were often very smooth. However, the ratio of height basal diameter of the septal granules was highly variable, resulting in a wide spectrum of shapes ranging from hemispherical to subcylindrical and spinose.

At the microstructural level, $L$. pertusa and $D$. dianthus skeletons showed very similar organization. In both taxa, the septa and wall consisted of two distinct microstructural zones: the so-called "mid-septal zone" (or "dark line") composed of densely packed Rapid Accretion Deposits (RADs) (Fig. 3c, d, h, i) and Thickening Deposits (TD) composed of bundles of fibers that radiate outwards from the RADs. The spatial relationship between septal and wall microstructural units transformed similarly during ontogeny starting as marginotheca, evolving into trabeculotheca and eventually forming septotheca (see Additional file 5: red, blue and orange arrows, respectively, in vertical columns outlining). During the earliest ontogenetic stages, thecal RADs remained connected to RADs of the adjacent septa. In transverse sections of coralla, this was recognized as a continuation of the "dark line" between septa and wall. This microstructural pattern corresponded to the stage when the rims (consisting of RADs) of the wall and septa were formed at the same 
Table 1 Pairwise species non-synonymous substitutions with nucleotide (NT) and amino acid (AA) location

\begin{tabular}{|c|c|c|c|c|c|c|c|c|c|c|c|c|c|c|c|c|c|c|c|c|c|c|c|c|c|c|c|c|c|c|c|}
\hline \multirow[b]{2}{*}{ \# } & \multirow[b]{2}{*}{ AA } & \multirow[b]{2}{*}{ NT } & \multirow[b]{2}{*}{ Gene } & \multicolumn{4}{|c|}{ Dd432-LpKC875348 } & \multicolumn{4}{|c|}{ Dd432-LpKC875349 } & \multicolumn{4}{|c|}{ Dd432-LpFR821799 } & \multicolumn{4}{|c|}{$D d 432-D d 636$} & \multicolumn{4}{|c|}{ Dd636-LpKC875348 } & \multicolumn{4}{|c|}{ Dd636-LpKC875349 } & \multicolumn{4}{|c|}{ Dd636-LpFR821799 } \\
\hline & & & & $\mathrm{AA}$ & & & & AA & & & & $\mathrm{AA}$ & & & & $\mathrm{AA}$ & & & & $\mathrm{AA}$ & & & & $\mathrm{AA}$ & & & & AA & & & \\
\hline 1 & 26 & 77 & nad5 & 26 & $\mathrm{R}$ & $==>$ & K & 26 & R & $==>$ & K & 26 & R & $==>$ & K & & & & & 26 & $R$ & $==>$ & K & 26 & R & $==>$ & K & 26 & $\mathrm{R}$ & $==>$ & K \\
\hline 2 & 38 & 113 & nad5 & 38 & $\mathrm{~T}$ & $==>$ & 1 & 38 & T & $==>$ & 1 & 38 & T & $==>$ & 1 & 38 & $\mathrm{~T}$ & $==>$ & 1 & & & & & & & & & & & & \\
\hline 3 & 165 & 493 & nad5 & 165 & V & $==>$ & 1 & 165 & V & $==>$ & 1 & 165 & V & $==>$ & 1 & 165 & V & $==>$ & 1 & & & & & & & & & & & & \\
\hline 4 & 351 & 1051 & nad1 & & & & & & & & & & & & & 351 & K & $==>$ & Q & 351 & $\mathrm{Q}$ & $==>$ & K & 351 & Q & $=\Rightarrow>$ & K & 351 & $\mathrm{Q}$ & $==>$ & K \\
\hline 5 & 427 & 1280 & nad1 & 427 & $c$ & $==>$ & $\mathrm{F}$ & 427 & $C$ & $==>$ & $\mathrm{F}$ & & & & & 427 & $c$ & $==>$ & $\mathrm{F}$ & & & & & & & & & 427 & $\mathrm{~F}$ & $==>$ & C \\
\hline 6 & 1403 & 4208 & $\operatorname{cox} 3$ & & & & & & & & & & & & & 1403 & $N$ & $==>$ & S & 1403 & S & $==>$ & $N$ & 1403 & S & $==>$ & $\mathrm{N}$ & 1403 & S & $==>$ & $\mathrm{N}$ \\
\hline 7 & 1408 & 4225 & $\cos 3$ & 1408 & G & $==>$ & S & 1408 & $G$ & $==>$ & s & 1408 & G & $==>$ & S & 1409 & $G$ & $==>$ & S & & & & & & & & & & & & \\
\hline 8 & 1499 & 4498 & $\cos 3$ & 1499 & $S$ & $==>$ & G & 1499 & S & $==>$ & G & 1499 & S & $==>$ & G & & & & & 1500 & S & $==>$ & G & 1500 & $S$ & $==>$ & G & 1500 & $S$ & $==>$ & G \\
\hline 9 & 1685 & 5056 & $\operatorname{cox} 2$ & 1685 & G & $==>$ & $R$ & 1685 & G & $=\Rightarrow$ & $\mathrm{R}$ & 1685 & G & $==>$ & R & 1686 & $G$ & $==>$ & R & & & & & & & & & & & & \\
\hline 10 & 2289 & 6865 & nad5 & & & & & & & & & 2288 & $\mathrm{E}$ & $==>$ & K & & & & & & & & & & & & & 2289 & $E$ & $==>$ & K \\
\hline 11 & 2471 & 7411 & $c o b$ & & & & & & & & & 2470 & $\mathrm{~T}$ & $==>$ & $\mathrm{P}$ & & & & & & & & & & & & & 2471 & $\mathrm{~T}$ & $==>$ & P \\
\hline 12 & 2698 & 8097 & $c o b$ & 2698 & $\mathrm{~L}$ & $==>$ & $\mathrm{F}$ & 2698 & $L$ & $==>$ & $\mathrm{F}$ & & & & & & & & & 2699 & L & $=\Rightarrow$ & $\mathrm{F}$ & 2699 & L & $==>$ & $\mathrm{F}$ & & & & \\
\hline 13 & 2863 & 8589 & nad2 & & & & & & & & & & & & & 2863 & $\mathrm{~F}$ & $==>$ & L & 2863 & L & $=\Rightarrow>$ & $\mathrm{F}$ & 2863 & L & $==>$ & $\mathrm{F}$ & 2863 & $\mathrm{~L}$ & $==>$ & $\mathrm{F}$ \\
\hline 14 & 2930 & 8789 & nad2 & & & & & & & & & & & & & 2930 & $\mathrm{H}$ & $==>$ & $\mathrm{R}$ & 2930 & $R$ & $=\Rightarrow$ & $\mathrm{H}$ & 2930 & R & $==>$ & $\mathrm{H}$ & 2930 & $\mathrm{R}$ & $==>$ & $\mathrm{H}$ \\
\hline 15 & 3054 & 9161 & nad2 & & & & & & & & & 3053 & L & $==>$ & S & & & & & & & & & & & & & 3054 & $\mathrm{~L}$ & $==>$ & $S$ \\
\hline 16 & 3087 & 9260 & nad6 & & & & & & & & & 3086 & L & $==>$ & $P$ & & & & & & & & & & & & & 3087 & L & $==>$ & P \\
\hline 17 & 3191 & 9574 & nad6 & 3191 & $Y$ & $==>$ & $\mathrm{H}$ & & & & & & & & & & & & & 3192 & $Y$ & $==>$ & $\mathrm{H}$ & & & & & & & & \\
\hline 18 & 3221 & 9664 & nad6 & 3221 & $\mathrm{~L}$ & $==>$ & 1 & 3221 & L & $==>$ & 1 & 3221 & L & $==>$ & 1 & & & & & 3222 & L & $==>$ & 1 & 3222 & L & $==>$ & 1 & 3222 & L & $==>$ & 1 \\
\hline 19 & 3348 & 10046 & $\cos 1$ & 3348 & A & $==>$ & V & 3348 & A & $=\Rightarrow>$ & v & 3348 & A & $==>$ & V & & & & & 3349 & A & $=\Rightarrow>$ & V & 3349 & A & $=\Rightarrow>$ & V & 3349 & A & $==>$ & V \\
\hline 20 & 3354 & 10064 & $\operatorname{cox} 1$ & 3354 & V & $==>$ & A & 3354 & V & $=\Rightarrow$ & A & 3354 & V & $==>$ & A & & & & & 3355 & V & $==>$ & A & 3355 & V & $==>$ & A & 3355 & V & $==>$ & A \\
\hline 21 & 3389 & 10166 & $\operatorname{cox} 1$ & & & & & & & & & 3388 & $S$ & $==>$ & $\mathrm{F}$ & & & & & & & & & & & & & 3389 & $S$ & $==>$ & $\mathrm{F}$ \\
\hline 22 & 3713 & 11141 & $\operatorname{cox} 1$ & 3713 & $\mathrm{R}$ & $==>$ & K & 3713 & $R$ & $==>$ & K & 3713 & $R$ & $==>$ & K & & & & & 3714 & $R$ & $==>$ & K & 3714 & $\mathrm{R}$ & $==>$ & K & & & & \\
\hline
\end{tabular}

Dd Desmoplyllum dianthus, L $L$ Lophelia pertusa 
Table 2 Computation of non-synonymous (dN) and synonymous (dS) substitutions between mitochondrial protein-coding genes of $D$. dianthus $(D d)$ and L. pertusa $(L p)$ using one approximate method (NG) and tree maximum-likelihood methods (GY-HKY; MS; MA) (Zhang et al. 2006) [79]

\begin{tabular}{|c|c|c|c|c|c|c|c|c|c|}
\hline Pairwise Sequence & Method & $\mathrm{Ka}=\mathrm{dN}$ & $\mathrm{Ks}=\mathrm{dS}$ & $\mathrm{Ka} / \mathrm{Ks}$ & $P$-value(Fisher) & Length & Substitutions & S-substitutions & $\mathrm{N}$-substitutions \\
\hline \multirow[t]{4}{*}{ Dd432-Dd636 } & NG & 0.00105426 & 0.00738853 & 0.14269 & $6.38 \mathrm{E}-02$ & 11127 & 28 & 19 & 9 \\
\hline & GY-HKY & 0.00103991 & 0.00780277 & 0.13328 & $3.46 \mathrm{E}-03$ & 11127 & 28 & 19.0493 & 8.9507 \\
\hline & MS & 0.00120913 & 0.00911783 & 0.13261 & $2.04 \mathrm{E}-02$ & 11127 & 28 & 16.8877 & 11.1123 \\
\hline & MA & 0.00111943 & 0.00849681 & 0.13175 & $2.57 \mathrm{E}-03$ & 11127 & 28 & 18.0081 & 9.9919 \\
\hline \multirow[t]{4}{*}{ Dd432-LpKC875348 } & $N G$ & 0.00151378 & 0.00618744 & 0.24465 & 0.000194732 & 11193 & 29 & 16 & 13 \\
\hline & GY-HKY & 0.00147761 & 0.00678233 & 0.21786 & $1.27 \mathrm{E}-01$ & 11193 & 29 & 16.0446 & 12.9554 \\
\hline & MS & 0.00145719 & 0.00716942 & 0.20325 & $5.85 \mathrm{E}-01$ & 11193 & 29 & 16.0453 & 12.9547 \\
\hline & MA & 0.00149592 & 0.0071832 & 0.20825 & $2.11 E+00$ & 11193 & 29 & 15.5980 & 13.4020 \\
\hline \multirow[t]{4}{*}{ Dd432-LpFR821799 } & $N G$ & 0.00174798 & 0.00657818 & 0.26572 & 0.000305985 & 11187 & 32 & 17 & 15 \\
\hline & GY-HKY & 0.00174679 & 0.00666052 & 0.26226 & 0.000133266 & 11187 & 32 & 17.0509 & 14.9491 \\
\hline & MS & 0.0017217 & 0.00701057 & 0.24559 & $2.37 \mathrm{E}+00$ & 11187 & 32 & 17.0472 & 14.9528 \\
\hline & MA & 0.00180584 & 0.00717326 & 0.25175 & 0.000138073 & 11187 & 32 & 15.9324 & 16.0676 \\
\hline \multirow[t]{4}{*}{ Dd432-LpKC875349 } & $N G$ & 0.00139724 & 0.00618725 & 0.22583 & 0.000111185 & 11193 & 28 & 16 & 12 \\
\hline & GY-HKY & 0.00135939 & 0.00686159 & 0.19812 & 5.55E-01 & 11193 & 28 & 16.0428 & 11.9572 \\
\hline & MS & 0.00134202 & 0.00722641 & 0.18571 & 2.64E-01 & 11193 & 28 & 16.0436 & 11.9564 \\
\hline & MA & 0.00138454 & 0.00726459 & 0.19059 & $9.52 \mathrm{E}-01$ & 11193 & 28 & 15.5516 & 12.4484 \\
\hline \multirow[t]{4}{*}{ Dd636-LpFR821799 } & $N G$ & 0.00187087 & 0.00542254 & 0.34502 & 0.00136247 & 11154 & 30 & 14 & 16 \\
\hline & GY-HKY & 0.00182133 & 0.00600644 & 0.30323 & 0.000711538 & 11154 & 30 & 14.0360 & 15.9640 \\
\hline & MS & 0.0019595 & 0.00650537 & 0.30121 & 0.00171439 & 11154 & 30 & 11.8204 & 18.1796 \\
\hline & MA & 0.00189377 & 0.00631826 & 0.29973 & 0.00217506 & 11154 & 30 & 12.8315 & 17.1685 \\
\hline \multirow[t]{4}{*}{ Dd636-LpKC875348 } & NG & 0.00140188 & 0.00542062 & 0.25862 & 0.00106907 & 11160 & 26 & 14 & 12 \\
\hline & GY-HKY & 0.00134558 & 0.00632621 & 0.21270 & $2.50 \mathrm{E}+00$ & 11160 & 26 & 14.0360 & 11.9640 \\
\hline & MS & 0.00134558 & 0.00632621 & 0.21270 & $2.50 \mathrm{E}+00$ & 11160 & 26 & 14.0360 & 11.9640 \\
\hline & MA & 0.00137335 & 0.00649319 & 0.21151 & $6.87 E+00$ & 11160 & 26 & 13.6246 & 12.3754 \\
\hline \multirow[t]{4}{*}{ Dd636-LpKC875349 } & NG & 0.00128497 & 0.00542045 & 0.23706 & 0.000405305 & 11160 & 25 & 14 & 11 \\
\hline & GY-HKY & 0.00122824 & 0.0064301 & 0.19101 & $1.05 E+00$ & 11160 & 25 & 14.0343 & 10.9657 \\
\hline & MS & 0.00122824 & 0.0064301 & 0.19101 & $1.05 E+00$ & 11160 & 25 & 14.0343 & 10.9657 \\
\hline & MA & 0.00124788 & 0.00657364 & 0.18983 & $3.68 \mathrm{E}-01$ & 11160 & 25 & 13.7456 & 11.2544 \\
\hline \multirow[t]{4}{*}{ LpKC875348-LpFR821799 } & $N G$ & 0.00092881 & 0.000768297 & 1.20892 & 0.954969 & 11223 & 10 & 2 & 8 \\
\hline & GY-HKY & 0.00088951 & 0.000903263 & 0.98477 & 0.929985 & 11223 & 10 & 1.9987 & 8.0013 \\
\hline & MS & 0.00088951 & 0.000903263 & 0.98477 & 0.929985 & 11223 & 10 & 1.9987 & 8.0013 \\
\hline & MA & 0.000874244 & 0.000974582 & 0.89705 & 0.605808 & 11223 & 10 & 1.9436 & 8.0564 \\
\hline \multirow[t]{4}{*}{ LpKC875348-LpKC875349 } & NG & 0.000115971 & NA & NA & NA & 11229 & 1 & NA & 1 \\
\hline & GY-HKY & 0.000117817 & $2.36 \mathrm{E}-06$ & 50.00000 & 0.367879 & 11229 & 1 & 0.0066 & 0.9934 \\
\hline & MS & 0.000117817 & $2.36 \mathrm{E}-06$ & 50.00000 & 0.367879 & 11229 & 1 & 0.0066 & 0.9934 \\
\hline & MA & 0.000108301 & $2.17 \mathrm{E}-06$ & 50.00000 & 0.367879 & 11229 & 1 & 0.0044 & 0.9956 \\
\hline \multirow[t]{4}{*}{ LpKC875349-LpFR821799 } & NG & 0.000812653 & 0.000768274 & 1.05776 & 0.941351 & 11223 & 9 & 2 & 7 \\
\hline & GY-HKY & 0.000778073 & 0.000903374 & 0.86130 & 0.589175 & 11223 & 9 & 1.9299 & 7.0701 \\
\hline & MS & 0.000778073 & 0.000903374 & 0.86130 & 0.589175 & 11223 & 9 & 1.9299 & 7.0701 \\
\hline & MA & 0.000756522 & 0.00100953 & 0.74938 & 0.272516 & 11223 & 9 & 2.0420 & 6.9580 \\
\hline
\end{tabular}


Table 3 Genetic divergence between $D$. dianthus $(D d)$ and $L$. pertusa $(L p)$ individuals using only putative control region sequences

\begin{tabular}{|c|c|c|c|c|c|c|c|c|c|c|c|c|c|c|c|}
\hline \# & Individuals & 1 & 2 & 3 & 4 & 5 & 6 & 7 & 8 & 9 & 10 & 11 & 12 & 13 & 14 \\
\hline 1 & LpFR821799 & - & & & & & & & & & & & & & \\
\hline 2 & LpKC875348 & 0.004 & - & & & & & & & & & & & & \\
\hline 3 & LpKC875349 & 0.004 & 0.000 & - & & & & & & & & & & & \\
\hline 4 & Lp|RL296 & 0.002 & 0.004 & 0.004 & - & & & & & & & & & & \\
\hline 5 & LpSML272 & 0.002 & 0.003 & 0.003 & 0.000 & - & & & & & & & & & \\
\hline 6 & DdARG472 & 0.108 & 0.110 & 0.110 & 0.107 & 0.090 & - & & & & & & & & \\
\hline 7 & DdAUS566 & 0.103 & 0.104 & 0.104 & 0.100 & 0.082 & 0.018 & - & & & & & & & \\
\hline 8 & DdMNZ601 & 0.098 & 0.100 & 0.100 & 0.098 & 0.093 & 0.132 & 0.125 & - & & & & & & \\
\hline 9 & DdSML62 & 0.114 & 0.113 & 0.113 & 0.114 & 0.110 & 0.115 & 0.106 & 0.034 & - & & & & & \\
\hline 10 & DdADR635 & 0.101 & 0.102 & 0.102 & 0.102 & 0.101 & 0.127 & 0.123 & 0.031 & 0.009 & - & & & & \\
\hline 11 & DdADR636 & 0.102 & 0.103 & 0.103 & 0.103 & 0.103 & 0.130 & 0.126 & 0.032 & 0.011 & 0.003 & - & & & \\
\hline 12 & DdIJC433 & 0.088 & 0.090 & 0.090 & 0.088 & 0.087 & 0.104 & 0.100 & 0.086 & 0.103 & 0.088 & 0.090 & - & & \\
\hline 13 & DdILC681 & 0.091 & 0.093 & 0.093 & 0.091 & 0.090 & 0.125 & 0.120 & 0.143 & 0.107 & 0.147 & 0.149 & 0.000 & - & \\
\hline 14 & DdIJC432 & 0.096 & 0.098 & 0.098 & 0.098 & 0.090 & 0.132 & 0.128 & 0.147 & 0.104 & 0.144 & 0.146 & 0.000 & 0.002 & - \\
\hline
\end{tabular}

level. The theca, which was relatively thin during the initial phase (thus juvenile coralla have relatively thin bases), was covered from the outside by successive thickening deposits (called tectura, see [49]), resulting in very thick bases in adults. The next main ontogenetic phase started with the formation of the trabeculotheca. In transverse sections, this phase was recognized due to the interruption of the primary marginotheca by radial elements and the formation of trabeculothecal segments [see 49]. This microstructural pattern corresponded to the phase when the rims of (mainly) primary septa expanded above and outside of the wall rim, which consequently formed only as "bridges" between septa. The last ontogenetic phase of wall development started when trabeculothecal segments were no longer in interseptal zones, and the only existing wall was one formed of thickened portions of septa, i.e. septotheca. The septothecate stage, characterized by the increase in septal thickness, often occurred earlier in L. pertusa than in D. dianthus (see Additional file 5 : b, h-d).

\section{Discussion}

Mitochondrial gene order rearrangement and its phylogenetic implications have recently been reported for several genera of Scleractinia [15-18]. However, none of these studies described two morphologically distinct genera sharing an extremely high level of genetic similarity. The analysis of $\mathrm{dN} / \mathrm{dS}$ ratios between the mitochondrial genomes of $L$. pertusa and $D$. dianthus indicates that sites are neutrally evolving. Of the approximately 16,000 bp per genome, more than $99 \%$ were identical between these two taxa. With only $25 \%$ of all differences identified as non-synonymous changes, any inferences on positive selection (or adaptation) would not be supported. Evidence of positive selection was detected for $L$. pertusa individuals from the Norwegian fjords and Mediterranean Sea, but without any evolutionary relevance [50]. Indeed, the positive selection found in this study (Table 2) was not statistically supported based on Fisher's exact test due to the low number of substitutions in protein-coding regions. As remarked also by Flot et al. [50] more sensitive statistical procedures, such as the $\mathrm{Z}$ test, require at least 10 synonymous and 10 non-synonymous mutations for assumptions to be met [51]. In the case of $L$. pertusa individuals from the Norwegian fjords and Mediterranean Sea, adaptive evolution was inferred because only one (non-synonymous) substitution was detected in more than $16,000 \mathrm{bp}$. Given the absence of synonymous substitutions, the resulting $\mathrm{dN} / \mathrm{dS}$ ratio was greater than 1 , indicating positive selection. Therefore, the values obtained in this study could be an artefact resulting from the analysis.

Even if Lophelia and Desmophyllum are considered as well established distinct genera, the genetic similarity and a very close phylogenetic relationship between $L$. pertusa and $D$. dianthus have been previously suggested $[24,44,47]$. In these studies, several molecular markers were used, including mitochondrial and nuclear genes, non-coding and protein-coding genes (exons and introns) and markers with distinct variation levels (e.g. nucleotide sequences and microsatellite genotyping). Independent of the type of molecular marker used in this study, resulting genetic distances between these two genera were always less than $1 \%$, and in many cases, were equal to zero. In contrast, genetic divergence between Desmophyllum and other caryophylliid genera (excluding Lophelia) ranged from 2 to $7 \%$ in both non-coding and protein-coding genes (see Additional file 1.5), showing a gene-dependent 
Table 4 Comparison of morphological characters observed in D. dianthus and L. pertusa $([20,28]$ and reference therein, [30], this study)

\begin{tabular}{lll}
\hline Characters & $D$. dianthus (adult corallum) & L. pertusa (adult corallite)
\end{tabular}

Corallum/Corallite shape

Calyx shape

Corallum/Corallite length (Max size)

Calicular diameter (Max size)

Calicular fossa

Columella

Calicular margin

\section{Septa cycles}

Axial margin

Septal granulation

\section{Tabulae}

Costae

Outer theca macro- and micromorphology

Theca thickness : GCD
Extremely variable. Typically trochoid with a subcylindrical pedicel, but also cylindrical, ceratoid, scolecoid

Elliptical to circular

\section{L: up to $20 \mathrm{~cm}$}

\section{GCD: up to $9 \mathrm{~cm}$}

Very narrow $(F w: L C D<1: 4)$ to large $(1: 3<F w: L C D<1: 2)$. Deep to very deep (Fd : $L C D>>2: 3)$

Rudimental, visible only in juvenile specimens

Flat to very jagged

\section{Up to 6 (incomplete)}

Straight and continuous, undulated in the proximal zone (more evident in juvenile specimens)

Typically cone-shaped, secondarily subcylindrical, rarely hemispherical; decreasing in size and density from proximal to distal corallum; locally coalescing to form irregular septal ridges

\section{Rare}

Typically acute (dominant septa) in the distalmost third of the corallum; rarely absent

Diffuse conical to hemispherical granulation, seldom preferential along flat costae; denser and more raised in the basal part where furrows can be present
Variable, generally ceratoid, but also trochoid and subcilindrical; often curve.

Circular to slightly elliptical, often irregular

\section{$\mathrm{L}$ : exceptionally longer than $4 \mathrm{~cm}$}

\section{GCD: up to $2 \mathrm{~cm}$}

Generally narrow $(1: 4<F w$ : $L C D<1: 3)$ to large $(1: 3<F w: L C D<1: 2)$. Deep to very deep ( $F d: L C D>>2: 3$ )

Rudimental, visible only in juvenile specimens

Flat to very jagged

\section{Up to 4 (exceptionally few septa of cycle 5)}

Straight and continuous, undulated in the proximal zone

Typically cone-shaped, secondarily subcylindrical, rarely hemispherical: decreasing in size and density from proximal to distal corallum; locally coalescing to form irregular septal ridges

\section{Common}

Acute (dominant septa) in the distalmost fourth of the corallum or absent

Diffuse granulation, seldom preferential along flat costae, denser and more raised in the proximal part

Variable; $0.04-0.4$ (mostly $0.06-0.14)$

Diagnostic characters clearly differentiating $D$. dianthus from $L$. pertusa (and vice versa) are indicated in bold

Abbreviations: $L$ length, $G C D$ greater calicular diameter, $L C D$ lower calicular diameter, $F_{w}$ width calicular fossa, $F_{d}$ fossa depth 


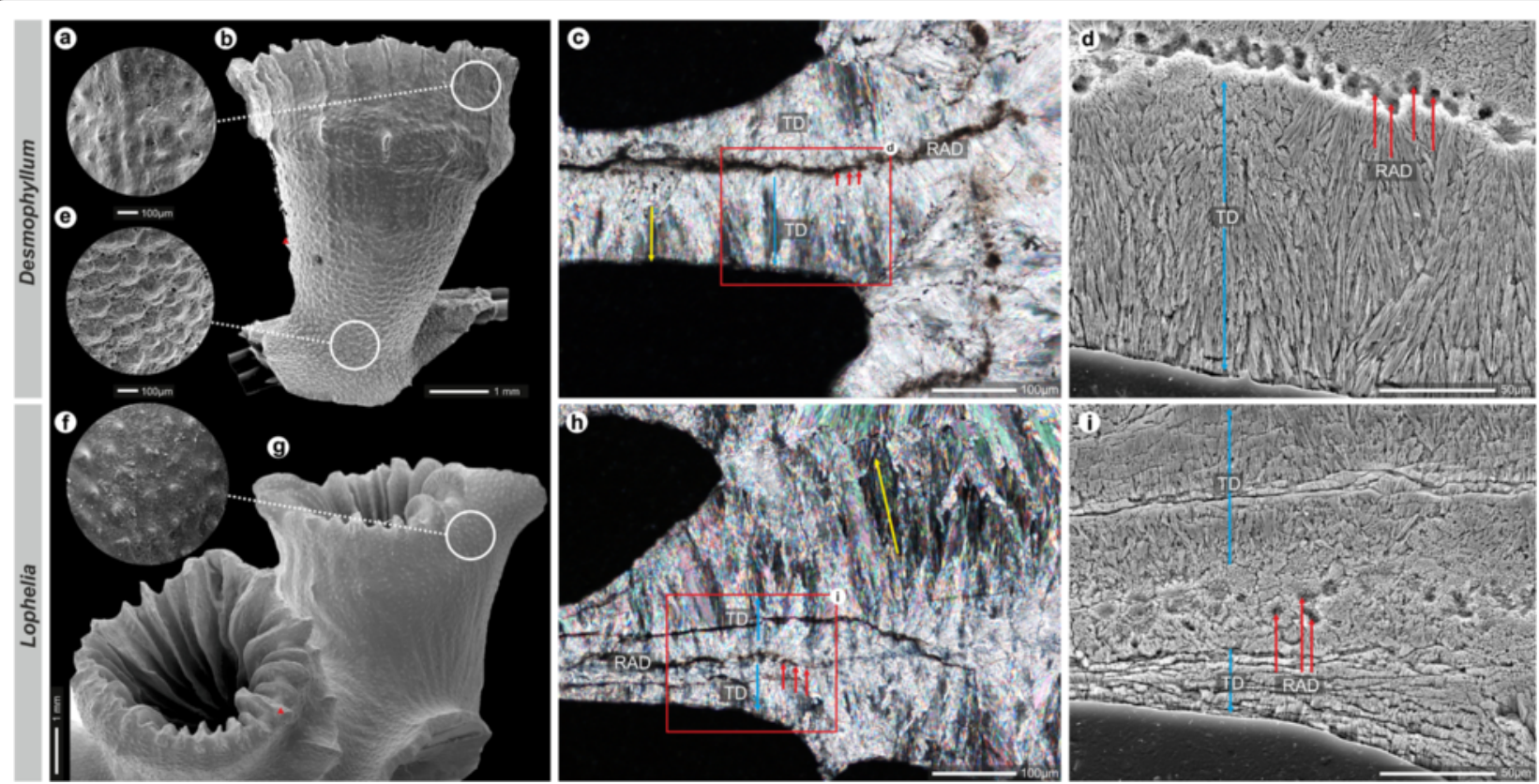

Fig. 3 Micromorphology (thecal granulations) and microstructure of Desmophyllum DdSML 188, a-e and Lophelia MEDCOR 09, f-i. Thecal granulations in both taxa are very similar: granules are typically denser and more rounded (hemispherical) in proximal portions of specimens (d) whereas more dispersed and spinose in distal portions ( $\mathbf{a}, \mathbf{e})$. Microstructural organization of septa of both taxa as viewed in transverse thin sections (c, $\mathbf{h}$ ) and polished and etched sections (d, i): the so called "mid-septal zone" consists of densely packed Rapid Accretion Deposits, RADs (red arrows) with Thickening Deposits, TD (blue arrows) radiating outward from the RADs. TD in the illustrated Desmophyllum form well organized, large bundles of fibers, whereas in Lophelia, few zones separated by clear crystal boundaries are recognizable. Yellow arrows (c, $\mathbf{h}$ ) mark complete light extinction of the fiber bundles in polarized light, indicating similar arrangement of axes of individual crystallographic domains

variation that correlates with the polymorphism level and mutation rate characterizing each marker. To date, a genetic threshold for clearly distinguishing species or genera has not been established, nor a consensus has been reached for defining a gene for universal DNA barcoding. The use of a genetic threshold or DNA barcoding is even more ambiguous if applied to Scleractinia, a taxonomic order characterized by slowing evolving mitogenomes and extensive interspecific hybridization [7, 52]. More than 1500 species of corals show a wide range of morphological variability and associated genetic incongruences at different phylogenetic levels [e.g. 53]. Furthermore, half of the scleractinian species live in the deep-sea, a more 'stable' habitat than tropical shallow waters, and therefore, are likely experiencing a different evolutionary rate.

The hypothesis that Lophelia and Desmophyllum have extremely slow evolution rates due to their preferential location in deep-water environments was tested using hypervariable genetic markers [24, 47]. Given the high mutation rates and level of polymorphisms, microsatellite markers are known to be powerful genetic tools for studying population structure. Microsatellites are usually designed to be species-specific markers; however, successful cross-species amplifications in related taxa are possible if the flanking regions of sequence repeats are conserved.
Indeed, the evolutionary conservation of flanking regions of monomorphic microsatellite loci has been used as a source of data for resolving species-level phylogenies in several groups, including plants, fishes, and birds [see 54-56]. Therefore, two closely related species can be differentiated by the polymorphism of sequence repeats, exhibiting variance in nucleotide sequence or allele size (expressed in units of repeat counts). As previously demonstrated [47], 30 microsatellites markers, initially developed for $D$. dianthus, were successfully used, with clear peak profiles, to genotype $L$. pertusa specimens. Indeed, individuals of $L$. pertusa from the Mediterranean Sea and North Atlantic Ocean showed the same allele size range as D. dianthus (see Additional file 1.3, Additional file 3).

Nevertheless, similar microsatellite electromorphs can arise from independent mutational events, and such alleles can be not identical by descent [57]. Given this phenomenon, termed size homoplasy, additional comparative analyses using microsatellite sequences were performed. A total of 37 loci, previously characterized for $L$. pertusa $[45,58]$ and published in GenBank, were used to perform multiple BLAST searches using TRUFA 0.8.2 [59], against D. dianthus genomic DNA libraries that were previously obtained by Illumina (data not shown) and 454 [47] sequencing. This analysis of microsatellite 
sequences showed that average sequence identities for 1368 separate pair-wise comparisons between $L$. pertusa and $D$. dianthus were about $97 \%$ similar.

Moreover, our data suggest that the putative mitochondrial control region may be a potential marker for investigating the phylogeography of the genera Lophelia [50] and Desmophyllum, though its usefulness in investigating species boundaries is uncertain. Interestingly, $D$. dianthus shows wide genetic divergence at the intraspecific level comparable to what is observed at the inter-generic level between Desmophyllum and Lophelia (Tables 1, 4, 2, see Additional file 1.1). Indeed, individuals that traditionally belong to the genera Lophelia and Desmophyllum are genetically more similar to each other than to individuals of the same genus (Desmophyllum) living in different regions (Chilean fjords vs Mediterranean Sea).

If $0.01-1 \%$ genetic divergence in mitochondrial genomes, combined with morphological differences, is a valid range at the interspecific level for genera within Scleractinia (e.g. Acropora divaricata vs Acropora aspera, and Porites okinawensis vs Porites panamensis, see Additional file 1.2a and 1.2b), the results of our study suggest that Chilean Desmophyllum "dianthus", with its apparently morphological variation, and Mediterranean and Atlantic L. pertusa and D. "dianthus" may be considered three different species within the same genus. However, no clear morphological differences have been found between Mediterranean/Atlantic and Chilean Desmophyllum [54]; therefore the specific distinction should be only based on genetic information.

On the other hand, although statistical significance has been found between $D$. dianthus from $L$. pertusa for the number of septa (see Additional file 1.4, Additional file 4), the only unequivocal feature that allows us to distinguish the two taxa is asexual reproduction by budding in $L$. pertusa. Occasionally distinct $D$. dianthus polyps touch each other and fuse, producing a common skeleton, though no evidence of budding (in the polyp nor skeleton) has been reported for this species thus far. Therefore, the two growth forms, colonial (L. pertusa) and solitary $(D$. dianthus), can be morphologically distinguished when the first polyp reproduces asexually. The calice of $D$. dianthus can also reach much larger sizes than the one of $L$. pertusa ( $L$. pertusa only rarely reach $20 \mathrm{~mm}$ in GCD) and, at equal GCD, almost always has a higher number of septa (see Additional file 1.4, Additional file 4). Moreover, though these two growth forms are commonly sympatric, in some cases, their relative dominance can be indicative of different environmental conditions, such as different habitats within the same area (e.g. Ionian Sea cold-water coral province [35, 36] or very distant geographic regions (e.g. Lophelia-dominated Norwegian fjords vs. Desmophyllum-dominated Chilean fjords). A clear distinction between the two growth forms is even easily detected in well-preserved fossil specimens recorded since the Early Miocene in periMediterranean on-land outcrops [28, 60, 61].

The striking genetic similarity between $L$. pertusa and $D$. dianthus calls into question their assignment to two distinct genera, which was primarily based on growth form and secondarily on very few skeletal features. In order to preserve (palaeo) ecological information but, at the same time, update the scleractinian classification following new molecular results (as recommended by the Scleractinia Working Group (SWG) [62]), D. dianthus and L. pertusa should be ascribed at least to the same genus.

The genus Desmophyllum Ehrenberg, 1834 was described before the genus Lophelia (Milne Edwards \& Haime, 1849). Thus, following the Principle of Priority of the International Code of Zoological Nomenclature (ICZN) [Art. 23.1] we propose that the solitary and the colonial species are ascribed herein to the genus Desmophyllum and are named Desmophyllum dianthus (Esper, 1794) and Desmophyllum pertusum (Linnaeus, 1758), respectively. Below we modify the diagnosis of the genus Desmophyllum based on the information acquired in this study. We also provide a short description of the most important skeletal features of the species Desmophyllum pertusum (Linnaeus, 1758). A comprehensive revision of the genus Desmophyllum, including fossil species, is currently in progress.

\section{Order: Scleractinia \\ ['Robust' Scleractinia Group] \\ Family: Caryophylliidae Dana, 1846}

Genus: Desmophyllum Ehrenberg, 1834

Diagnosis: Corallum solitary or colonial. Corallum of solitary species greatly variable in shape, trochoid with subcylindrical pedicel or cylindrical, ceratoid, scolecoid. Colonial corallum bushy in shape, often with anastomosing branches. Up to 6 cycles of septa non-hexamerally arranged. Pali absent. Columella poorly developed, visible only in early developmental stages. Septothecal wall in ontogenetically adult corallites commonly covered by thickening deposits.

Type species: Madrepora dianthus Esper, 1794, pl. 69, Figures 1, 2, 3; subsequent designation Cairns, 1994, p. 76

Recent species included: Desmophyllum striatum Cairns, 1979-for description see Cairns (1979:120), Desmophyllum quinarium Tenison-Woods, 1879-for description see Tenison-Woods (1879:18), Desmophyllum dianthus (Esper, 1794)-for description see Cairns (1979:26), Desmophyllum pertusum (Linnaeus, 1758)

Desmophyllum pertusum (Linnaeus, 1758) comb. nov. Madrepora pertusa Linnaeus, 1758: 38, pl. 2, Figures 1, 2. 
Lophelia pertusa Zibrowius, 1980: 126, pl. 66 a-l (synonymy).-Cairns, 2000: 100-102 (synonymy).

Lophelia prolifera Cairns, 1979: 125-127, pl. 24, Figures 1, 2, 3, 4, 5 (synonymy).

Diagnosis: Corallum forming large bushy colonies. Corallite skeleton connected to the parental one at least in the early growth stage (Fig. 1b). Corallites only exceptionally longer than $4 \mathrm{~cm}$ and up to $2 \mathrm{~cm}$ in maximum calicular diameter. Septa irregularly arranged in 4 cycles, only exceptionally in 5 incomplete ones. Common tabulae.

Remarks: The species has been widely described, as belonging to the genus Lophelia ([e.g., 20, 21, 27, 28, 63] and reference therein, [28]). The diagnosis reported herein includes only the skeletal characters that, at this stage of knowledge, lead us to distinguish $D$. pertusum from $D$. dianthus.

Insufficient information about $D$. dianthus and $D$. pertusum ecology and biology lead to be "conservative" in the taxonomic rearrangement. The difference in the geographical distribution, growth form (i.e. ontogenetic development), might be weak characters from a taxonomic point of view to maintain $D$. dianthus and $D$. pertusum as sympatric species. Detailed studies on the systematics of the genus Desmophyllum, currently on-going, might lead to synonymise these two species. Further research on biogeography and reproduction of the genus are needed to support (or not) this taxonomic distinction. If differences of environmental features and ontogenetic mechanism would not be statistically significant to support species differentiation, the comparison of molecular data performed in this study (including 5 complete mitochondrial genomes, 30 microsatellites, and 18 between protein and non protein-coding genes-Addamo, pers. obs.) would demonstrate that $D$. dianthus and $D$. pertusum are the same species. In such a case, following the rule of priority by date of publication of the International Code of Zoological Nomenclature (ICZN) [Art. 23.1], since the species $D$. dianthus (Esper, 1794) was described after D. pertusum (Linnaeus, 1758), both species would be named as D. pertusum.

Our findings pose questions about the molecular and developmental basis of colony formation in scleractinian corals and the taxonomic value of this character. Many lines of evidence show that in Cnidaria asexual budding and colony formation are controlled by differentially expressed genes. For example, Notch-a classical developmental signalling pathway, among other functions-is involved in asexual budding in Hydra (Hydrozoa), Nematostella (sea anemone), and Acropora (scleractinian) [see 64-66]. Taking into account the overwhelming genetic similarity between Lophelia and Desmophyllum, one may hypothesize that the same developmental mechanisms (i.e. Notch) regulate the solitary vs colonial growth forms of these taxa. There are several other examples of closely related scleractinians (genera, species) that display a variety of growth forms. For example, (1) Anomocora carinata includes both colonies sensu stricto (fully integrated) and "quasicolonial" forms in which "the daughter corallites [break] free of the parent before a third generation bud appears" [67], (2) Rhizosmilia maculata and Dendrophyllia cornigera show both colonies s.s. and "loosely integrated" colonies in which partial colonial mortality may yield solitary daughter polyps [20, 67], and (3) Balanopsammia wirtzi is represented by both solitary and partly to fully integrated colonies [68]. All these examples call into question the robustness of this widely used genus-level criterion, i.e. the occurrence of solitary vs colonial growth forms [69-71]. Further studies that recognize links between molecular and morphological characters [alike 25, 62, 72-74] and that focus on developmental (transcriptomic) mechanisms may help elucidate the basis of morphological and developmental mechanism variability and provide a robust taxonomic framework of Scleractinia.

\section{Conclusions}

Molecularly and morphologically, solitary Desmophyllum dianthus and dendroid Lophelia pertusa appear to be significantly more similar to each other than other unambiguous coral genera analysed to date. Thus, following the ICZN, we propose to ascribe these two species to the genus Desmophyllum and to name them as $D$. dianthus and $D$. pertusum. Findings of this study may have broader implications that should lead to re-consider the taxonomic value of growth forms (solitary vs colonial), traditionally used to distinguish scleractinian genera. Further integrative studies combining molecular, developmental biology and ecological environmental studies are required to test the potential conspecificity of $D$. dianthus and $D$. pertusum and provide more insights into the evolution of Scleractinia.

\section{Methods}

\section{Sample collection and study area}

The coral specimens selected for genetic analysis were collected during several oceanographic expeditions (Additional file 1.6) authorized by the competent maritime authorities off-shore Italy, Ireland, Argentina, Chile, Tasmania and Australia. The CORSARO 39 and MEMA12 cruises were carried out in the frame of EU projects Hermes (GOCE-CT-2005-511234-1) and FP7 Hermione (grant agreement no: 226354). The Eurofleets Moira Mound cruise [75] was funded by the European Union Seventh Framework Programme (EU-FP7/2007-2013) 
under the Eurofleets grant agreement n. 228344. The expedition in the Chilean fjords was performed in the frame of Spanish project funded by Spanish Research Council (CSIC) and Endesa Foundation.

Some of the coral specimens used for skeletal analysis (Additional file 1.4) were genetically analysed by [24]. The other specimens were collected dead 1) off-shore Ireland during the Eurofleets Moira Mound cruise (see above), 2) off-shore Morocco (during the Genesis 2 and MD194 $[76,77]$ cruises, framed within the EU-FP7 Hermione and Eurofleets projects (see above), respectively) and 3) off-shore Italy (during the MAGIC-CoralFISH and METEOR 70-1 cruises). The Magic-CoralFISH cruise [78] was funded by the EU-FP7 CoralFISH Project (grant agreement n. 213144) and the MAGIC Project by the Italian National Research Council. Details about the METEOR 70-1 cruise can be found in [33].

After collection, all specimens were preserved in absolute ethanol. Samples were transported to Spain with appropriate export and import permits following the Convention on International Trade in Endangered Species of wild Fauna and Flora (CITES). This study did not involve endangered or protected species listed in the IUCN Red List of Threatened Species.

\section{Genetic analysis}

For amplification of the complete mitochondrial genome, two samples of $D$. dianthus were collected in two distant localities: 1$)$ South Adriatic Sea $\left(39^{\circ} 53^{\prime} 468^{\prime \prime} N, 18^{\circ}\right.$ $55^{\prime} 176$ "E), off shore of Tricase (Italy, Mediterranean Sea), sampled at a depth of $786 \mathrm{~m}$ by the R/V Urania during CNR cruise MEMA12 during April to May 2012 and 2) Isla Jaime (43⒋ $\left.46^{\prime} 34.23^{\prime \prime} \mathrm{S}, 72^{\circ} 55^{\prime} 13.057^{\prime \prime} \mathrm{W}\right)$, located in the Pitipalena Fjord (Chile, South Pacific Ocean), sampled at a depth of $23 \mathrm{~m}$ by SCUBA diving in February 2012.

For additional sequence comparisons of the putative control region, 7 samples of $D$. dianthus and 2 of $L$. pertusa were collected in 10 distinct localities distributed in the northern and southern hemispheres. Specimen information is found in Additional file 1.6.

\section{DNA extraction and mitochondrial genome sequencing}

Genomic DNA was extracted from the mesenteric tissue of each specimen using the QIAGEN BioSprint 15 DNA Blood Kit (Qiagen Iberia S.L., Madrid, Spain), with slight modifications, including the optional RNase treatment and an extended period of proteinase $\mathrm{K}$ lysis (overnight incubation at $55{ }^{\circ} \mathrm{C}$ ). The DNA was quantified using a Qubit 2.0 Fluorometer and diluted to a final concentration of $2 \mathrm{ng} / \mu \mathrm{l}$.

Several overlapping fragments, covering the entire mitogenome, were amplified by PCR mainly using primers previously designed for L. pertusa [50], though one specific primer pair was designed using PRIMER3 [79] (Table 5). PCRs were carried out in a total volume of $50 \mu \mathrm{l}$ with $1 \mathrm{x}$ PCR Biotools Standard Reaction Buffer including $2 \mathrm{mM}$ $\mathrm{MgCl}_{2}, 0.5 \mu \mathrm{M}$ forward and reverse primers, $0.2 \mathrm{mM}$ of each dNTP, 1.5U DNA polymerase (Biotools), and $2 \mathrm{ng}$ of template DNA. PCR amplifications were performed in a Veriti $^{\text {min }}$ Thermal Cycler (Applied Biosystems) with the following cycle conditions: an initial denaturing step of $94{ }^{\circ} \mathrm{C}$ for $5 \mathrm{~min}$, followed by 35 cycles of $30 \mathrm{~s}$ at $94{ }^{\circ} \mathrm{C}$, an annealing step of $30 \mathrm{~s}$ at $53{ }^{\circ} \mathrm{C}$, an extension step of $1-3 \mathrm{~min}$ at $72{ }^{\circ} \mathrm{C}$, and a final extension of $10 \mathrm{~min}$ at $72{ }^{\circ} \mathrm{C}$. PCR products were purified using GELase ${ }^{\mathrm{mm}}$ Agarose Gel-Digesting Preparation (Epicentre, Madison, WI, USA), following the Fast Protocol. If a specific PCR product was not amplified under these conditions, three other annealing temperatures $\left(\mathrm{T}_{\mathrm{A}} 48,50\right.$, or $\left.51{ }^{\circ} \mathrm{C}\right)$ were tested with the same cycling conditions. Failing that, PCR amplifications were carried out as above but in a total volume of $20 \mu \mathrm{l}$ and with $2 \mathrm{U}$ DNA polymerase (MyTaq). In these cases, PCR amplifications were performed with the following cycle conditions: an initial denaturing step at $95{ }^{\circ} \mathrm{C}$ for $5 \mathrm{~min}$, followed by 40 cycles of $15 \mathrm{~s}$ at $95{ }^{\circ} \mathrm{C}$, an annealing step of $30 \mathrm{~s}$ at $50{ }^{\circ} \mathrm{C}$, an extension step of $1-3 \mathrm{~min}$ at $72{ }^{\circ} \mathrm{C}$, and a final extension of $10 \mathrm{~min}$ at $72{ }^{\circ} \mathrm{C}$.

To amplify the putative control region, PCR amplifications were performed in total volume of $20 \mu \mathrm{l}$ with $1 \mathrm{x}$ PCR OptiBuffer Reaction Buffer including $3 \mathrm{mM} \mathrm{MgCl} 2$, 1x Hi-Spec Additive, $0.5 \mu \mathrm{M}$ forward and reverse primers, $0.5 \mathrm{mM}$ of each dNTP, 2U DNA polymerase (BIO-X-ACT Short), and 2 ng of template DNA. PCR amplifications were performed with the following cycle conditions: an initial denaturing step at $95{ }^{\circ} \mathrm{C}$ for $5 \mathrm{~min}$, followed by 30 cycles of $30 \mathrm{~s}$ at $94{ }^{\circ} \mathrm{C}$, an annealing step of $30 \mathrm{~s}$ at $56{ }^{\circ} \mathrm{C}$, an extension step of $2 \mathrm{~min}$ at $72{ }^{\circ} \mathrm{C}$, and a final extension of $10 \mathrm{~min}$ at $72{ }^{\circ} \mathrm{C}$.

Individual amplicons were cloned into pGEM-T vectors (Promega, Madison, WI, USA), were purified using the Wizard Plus SV Minipreps DNA Purification System (Promega, Madison, WI, USA), following the Centrifugation Protocol, and sequenced on ABI PRISM 3730 DNA Sequencer (Applied Biosystems), following the Poly-A/T Protocol (Secugen S.L.) using specific primers, M13 universal primers and, if necessary, internal (walking) primers to cover the total length of the fragments (Table 5).

The complete mitogenomes and sequences reported in this paper were deposited in GenBank (NCBI).

\section{Sequences alignment, annotation and analyses}

Sequence chromatograms were verified, and primer sequences removed using Sequencher v.4.10.1 (Gene-Code Corporation). Genomic sequences were confirmed using BLAST (NCBI), assembled using Sequencher v4.10.1, 
Table 5 Primers pairs used for amplification and sequencing

\begin{tabular}{|c|c|c|c|}
\hline Oligo name & Oligo sequence (5' to $3^{\prime}$ ) & Fragment length (bp) & Reference \\
\hline LD1F & AAATCAAACGAGATTCCGAGAG & 1198 & Flot et al. 2013 [50] \\
\hline LD1R & TCCATGGGGACTTCTCGTC & - & Flot et al. 2013 [50] \\
\hline LD2F & TCGACTGTTTACCAAAAACATAGC & 1519 & Flot et al. 2013 [50] \\
\hline LD2R & AAYAACCTTCCATTGCATCC & - & Flot et al. 2013 [50] \\
\hline LD3F & TAGGAGTGGTTGGGAAATCG & 2563 & Flot et al. 2013 [50] \\
\hline LD3R & CTTGGGGAAGCCAAATATGA & - & Flot et al. 2013 [50] \\
\hline LD4F & GAACAACAGGGGCAACAGAT & 2127 & Flot et al. 2013 [50] \\
\hline LD4R & ATGGTGTCCCTGAAAAGTCG & - & Flot et al. 2013 [50] \\
\hline LD5F & GCAGACGCGGTGAAACTTA & 2521 & Flot et al. 2013 [50] \\
\hline LD5R & TACCCCGGCTAAGACAACTG & - & Flot et al. 2013 [50] \\
\hline LD6F & TTGTGGGGCAAATCATTCTT & 1034 & Flot et al. 2013 [50] \\
\hline LD6R & AATGAGAAAGCCCACAAGCA & - & Flot et al. 2013 [50] \\
\hline LD7F & CAACTCCGGTTTCTGCCTTA & 3060 & Flot et al. 2013 [50] \\
\hline LD7R & TTAAAAGAAAACTATGGAGGCCTAA & - & Flot et al. 2013 [50] \\
\hline LD8F & TTATTGGGCCTGTGTTGGT & 1604 & Flot et al. 2013 [50] \\
\hline LD8R & CCCACATATGAAAAGGAGCAAC & - & Flot et al. 2013 [50] \\
\hline LD9F & TGGGTGCTCTITCTTCTGGT & 1237 & Flot et al. 2013 [50] \\
\hline LD9R & AAATCCAATTGGTATATAATTTGTCA & - & Flot et al. 2013 [50] \\
\hline LD10F & ATCCCTCCTTTTGCAGGATT & 868 & Flot et al. 2013 [50] \\
\hline LD10R & CCCCAGAAGCTGTTGTGTTT & - & Flot et al. 2013 [50] \\
\hline LD11F & GGCAATTGGTTCTGGGATAA & 1254 & Flot et al. 2013 [50] \\
\hline LD11R & AAGCATACTAAAAGCCGTTCCA & - & Flot et al. 2013 [50] \\
\hline LD12F & TCTACAAACCACAAAGATATCGG & 930 & This study \\
\hline LD12R & AATCCCCGTAGGAACAGCAA & - & This study \\
\hline LD13F & GCCGGTGCTATTACAATGCT & 1892 & Flot et al. 2013 [50] \\
\hline LD13R & CAATCGATTCAAGCTCTITTCA & - & Flot et al. 2013 [50] \\
\hline 1a.PWF & CCATGTCCCACGGTTTATGT & - & This study \\
\hline 1b.PWR & AGGCCCAACTAACCTTCCAT & - & This study \\
\hline 2a.PWF & CATGGCGATTTCTTCTGTGA & - & This study \\
\hline 2b.PWR & CCCCGTCACACTTATGATCC & - & This study \\
\hline 3.PWF & GAAGCTITTGTCATGCTTCCTT & - & This study \\
\hline 4a.PWF & TGTGGAGTTTTCTCCTTGACC & - & This study \\
\hline 4b.PWR & AAGCTAACGTCTCGCCTTCA & - & This study \\
\hline 5a.PWF & GGTTGTGGCTTGTGGTCTTT & - & This study \\
\hline 5b.PWR & GCCCTCAAGGCAAAACATAA & - & This study \\
\hline 6a.PWF & ACAGTCGGGGCAAGTTITTA & - & This study \\
\hline 6b.PWR & ACCAAACACAGGCCCAATAA & - & This study \\
\hline
\end{tabular}

Abbreviations: $P W$ primer walking

and then compared with three previously published $L$. pertusa mitogenomes $[15,50]$ (see Additional file 1.7).

Open reading frames (ORFs) were identified using ORF Finder (available online at http://www.bioinformatics.org/ sms2/orf_find.html), with search parameters set to codon length $>50$ amino acids and the Coelenterate Mitochondrial Code translation. Transfer RNA genes were identified using tRNAscan-SE 1.21 [80] (available online at http://lowelab.ucsc.edu/tRNAscan-SE/). Additional automatic annotations were performed with DOGMA [81] (available online at http://dogma.ccbb.utexas.edu/), using high COVE threshold for mitochondrial tRNAs $(=30)$ and MITOS [82] (available online at http://mitos.bioinf. uni-leipzig.de/index.py). The mitochondrial protein-coding 
genes were compared to calculate non-synonymous $(\mathrm{dN})$ and synonymous $(\mathrm{dS})$ substitution rates through model selection and model averaging using three different methods based on Maximum-Likelihood, implemented in KaKs_Calculator [83].

To compare the genomes of a larger range of species, 50 previously published coral mitogenomes, representing 5 families and 15 genera of the Scleractinia Order, were retrieved from GenBank and aligned in ClustalW [84], using the default settings (see Additional file 1.7). The resulting alignments were manually checked and adjusted with Se-Al v.2.0a11 [85]. Estimation of genetic divergence between pairs of taxa, using uncorrected p-distances, were calculated in PAUP*v4.0a134 [86]. To estimate genetic divergence among genera and families of corals, mean uncorrected p-distances were calculated in Sequencer 6.1 (shareware written by B. Kessing).

Additional comparative analyses were performed using previously characterized microsatellite sequences for $L$. pertusa (37 loci $[45,58]$ ) and D. dianthus (30 loci $[47,87])$. Multiple BLAST searches of the genomic DNA libraries of both species were performed using TRUFA 0.8 .2 [59].

\section{Skeletal analysis}

The main differences and similarities between coralla and corallites of $D$. dianthus and L. pertusa, respectively (Table 4), were identified based on observations of 200 selected specimens (see Additional file 1.4) and data from the literature $[20,27,41,48]$. To assess comparable skeletal features of $D$. dianthus and $L$. pertusa, individuals were selected based on having a Greater Calicular Diameter (GCD) between 4 and $16 \mathrm{~mm}$. This GCD range is a relevant parameter for the following reasons: 1) both species have sizes within this GCD range; 2) $L$. pertusa rarely has corallites with a GCD $>16 \mathrm{~mm}$; 3) corallites with a GCD $<4 \mathrm{~mm}$ are indistinguishable between $D$. dianthus and $L$. pertusa species, and among other caryophylliids. The normality of number of septa distribution has been tested for each species and, once it was confirmed, a Student's two-tailed $t$-test has been performed for each parameter for both species. Analyses of septal and outer wall granulations were carried out on specimens selected for genetic analyses (see Additional file 1.4). Skeletal micromorphology was examined by SEM: specimens were mounted using silver glue, sputter-coated with conductive gold or platinum and analysed using a Vega Tescan (University of MilanoBicocca) or Phillips XL20 (Institute of Paleobiology, Warsaw) scanning electron microscope. Microstructural and ontogenetic data were obtained from serial transverse thin sections of coralla observed under a conventional transmitted light microscope. Polished sections were examined using a Nikon Eclipse 80i transmitted light microscope fitted with a DS-5Mc cooled camera head (Institute of Paleobiology, Warsaw). Supplementary ontogenetic micro-CT data were collected with a Zeiss XRadia MicroXCT-200 system equipped with a $90 \mathrm{kV} / 8 \mathrm{~W}$ tungsten X-ray source at the Laboratory of Microtomography, Institute of Paleobiology, Warsaw. Scans were performed using the following parameters: voltage $=$ $60 \mathrm{kV}$, power $=8 \mathrm{~W}$, pixel size ca. $21 \mu \mathrm{m}, 1601$ projections per sample, exposure time $4 \mathrm{~s}$. Radial projections were reconstructed with XMReconstructor software. The major changes in ontogenetic development were described following an ontogenetic sequence of thecal structures proposed by Stolarski [49]. Skeletal microstructural terminologies, namely the recognition of two main microstructural components, Rapid Accretion Deposits (RAD; also called Centers of Calcification) and Thickening Deposits (TD; also called fibers), were used according to Stolarski [88].

\section{Ethics approval and consent to participate}

Not applicable.

\section{Consent for publication}

Not applicable.

\section{Availability of supporting data}

The DNA sequences supporting of this article are available in [GenBank] database [Accession Numbers KX000882-KX000894].

The new taxon name and this article are registered in [ZooBank] registry with an identifier code [urn:lsid:zoobank. org:act:949C5CE4-4841-423 F-958D-A8D6A4E65E6B].

\section{Additional files}

\begin{abstract}
Additional file 1: 1.1 Annotation of the complete mitochondrial genome of D. dianthus (Dd) and L. pertusa (Lp) using DOGMA (Wayman et al. 2014) [77]. 1.2 Genetic divergences among scleractinian species. a. Genetic divergences among mitochondrial genomes of scleractinian species. b. Minimum (MIN) and maximum (MAX) value of genetic divergences (in percentage) among mitochondrial genomes of scleractinian species at inter-and intrageneric taxonomic level. $\mathbf{1 . 3}$ Comparison of D. dianthus and L. pertusa allele sizes for 30 microsatellite loc [47]. 1.4 Measurements of Great Calicular Diameter (GCD) and septa number (Septa N.) for 200 specimens of D. dianthus and L. pertusa. 1.5 Genetic divergence between $D$. dianthus $(D d)$ and $L$. pertusa $(L p)$, or other Dd individuals, Caryophyllia species (C. spp), or other hexacorallian species (Outgroup) [24]. 1.6 Depth, technique, geographic coordinates and other information for samples analysed in this study. $\mathbf{1 . 7}$ List of mitochondrial genomes analysed in this study with associated GenBank accession numbers (updated July 2014). (XLSX 53 kb)
\end{abstract}

Additional file 2: Synonymous and non-synonymous substitutions within the mitochondrial genomes of three individuals of L. pertusa and two of D. dianthus. (PDF $75 \mathrm{~kb}$ )

Additional file 3: Plots showing the allele size frequency per loci of $D$. dianthus (blue) and L. pertusa (red) for the 30 new microsatellites markers developed and described in Addamo et al. [47]. (PDF $2595 \mathrm{~kb}$ ) 
Additional file 4: Plot showing the relationship between the Greate Calicular Diameter (GCD in $\mathrm{mm}$ ) and number of septa $(S)$ in juvenile coralla of D. dianthus (blue diamonds) and L. pertusa (red diamonds). At equal GCD, the number of septa is normally higher in $D$. dianthus than in L. pertusa; there is also larger variability in septal number at a given GCD in D. dianthus than L. pertusa. (PDF $61 \mathrm{~kb}$ )

Additional file 5: Ontogenetic and microstructural skeletal features of Desmophyllum dianthus (Dd ROC 180, a, e, i, m, r, v—virtual mCT sections; $b, f, j, n, s, w$-thin sections, transmitted light microscope) and Lophelia pertusa (MEDCOR 09, c, g, k, o, t, z-virtual mCT sections; d, h, l, p, u, $x$-thin sections, transmitted light microscope). In both taxa, spatial relationships between the septa and wall transform similarly during ontogeny, described as a thecal sequence from marginotheca (red arrows) to trabeculotheca (blue arrows) to septotheca (orange arrows in vertical columns). Virtual mCT sections (left column for each taxon) correspond to the phases of growth depicted in transverse thin sections (right column for each taxon). Septotheca typically develops slightly later in the ontogeny of Desmophyllum (see length of orange arrows). Microstructural organization of coralla of both taxa is very similar and simple: septa and wall consist of densely packed Rapid Accretion Deposits, RAD (traditional "centers of calcification") and Thickening Deposits, TD (traditional fibers), which radiate outward (in transverse sections) from RADs. (PDF $12352 \mathrm{~kb}$ )

\section{Competing interests}

We have no competing interests.

\section{Authors' contributions}

AA and RGJ carried out the molecular lab work. AA performed data analysis, carried out sequence alignments, participated in the design of the study and drafted the manuscript; AV and JS carried out the morphological and statistical analyses, contributed in the interpretation of data, drafted the manuscript and contributed critically for important intellectual content; AA, AV, JS and MT collected field data; AA and AM conceived of the study, designed the study, and coordinated the study. All authors read and gave final approval for publication.

\section{Acknowledgements}

We acknowledge the captain, crew and scientific parties on board the RRW Meteor, Urania, Belgica, Universitatis, Marion Dufresne, and Celtic Explorer for their collaboration at sea during the following oceanographic cruises: M70-1, CORSARO, MEDCOR 2009, Belgica 2009/14, Belgica 2012/16 ("CWC Moira Mound", FP7/2007-2013 EuroFLEETS under grant agreement $n^{\circ} 228344$ ), Magic/CoralFISH 2010, MD194 ("Gateway", FP7/2007-2013 EuroFLEETS under grant agreement $n^{\circ}$ 228344). We further acknowledge the EU FP6 Hermes (GOCE-CT-2005-511234-1) and FP7 Hermione programmes Hermione (grant agreement no: 226354). The authors are particularly grateful to Karen Miller (Australian Institute of Marine Science), Virginia Polonio and Javier Cristobo (Instituto Español de Oceanografía) for providing samples from South Pacific Ocean (Expeditions S502/2007, TAN 0803) and South Atlantic Ocean (Patagonia 0209) respectively. We are grateful to Melinda Modrell for carefully revising the English version. The first author is deeply grateful to Felipe Gonzalez (Reserva Añihue) and Flavio Gaspari for fieldwork help in Chile, and to Miguel Angel Alonso-Zarazaga (Museo Nacional de Ciencias Naturales, MNCN-CSIC) for his valuable help with the International Code of Zoological Nomenclature (ICZN). Micro-CT scans were performed in the NanoFun laboratory (Institute of Paleobiology, Warsaw, Poland) and cofinanced by the European Regional Development. We thank the editor of the journal and two anonymous referees for comments and suggestions that improved the text. Ismar-Bologna scientific contribution n. 1871. We acknowledge support of the publication fee by the CSIC Open Access Publication Support Initiative through its Unit of Information Resources for Research (URICI).

\section{Funding}

This research was supported by the Spanish Ministry of Science and Innovation (CGL2011-23306 and CTM2014-57949R) and EU CoCoNET- "Towards COast to COast NETworks of marine protected areas (from the shore to the high and deep sea), coupled with sea-based wind energy potential" - from the VII FP of the European Commission under grant agreement $n^{\circ} 287844$. This paper also benefited from the ESF COCARDE network activities and commits to the Italian
Flag Project 'Ritmare'. Fund within the Innovation Economy Operational Programme POIG.02.02.00-00-025/09 (the help of K. Janiszewska is greatly appreciated).

\section{Author details}

${ }^{1}$ Departamento de Biodiversidad y Biología Evolutiva, Museo Nacional de Ciencias Naturales (MNCN-CSIC), José Gutiérrez Abascal 2, 28006 Madrid, Spain. ${ }^{2}$ Dipartimento di Scienze dell'Ambiente e del Territorio e di Scienze della Terra, Università di Milano Bicocca (UNIMIB), Piazza della Scienza 4, 20126 Milan, Italy. ${ }^{3}$ Department of Geology Renard Centre of Marine Geology, Universiteit Ghent, Krijgslaan 281, B-9000 Ghent, Belgium. ${ }^{4}$ Polskiej Akademii Nauk, Instytut Paleobiologii, Twarda 51/55, PL-00-818 Warsaw, Poland. ${ }^{5}$ Consiglio Nazionale delle Ricerche, Istituto di Scienze Marine (ISMAR), Via Gobetti 101, 40129 Bologna, Italy. ${ }^{6}$ Biology Department, Woods Hole Oceanographic Institution, 266 Woods Hole Road, Woods Hole 02543 , MA, USA. ${ }^{7}$ Stazione Zoologica Anton Dohrn, Villa Comunale, 80121 Naples, Italy.

\section{Received: 19 October 2015 Accepted: 12 April 2016}

Published online: 18 May 2016

\section{References}

1. Curole J, Kocher T. Mitogenomics: digging deeper with complete mitochondrial genomes. Trends Ecol Evol. 1999:14:394-8.

2. Irisarri I, San Mauro D, Green DM, Zardoya R. The complete mitochondrial genome of the relict frog Leiopelma archeyi: insights into the root of the frog tree of life. Mitochondrial DNA. 2010;21:173-82.

3. Duchêne S, Archer FI, Vilstrup J, Caballero S, Morin PA. Mitogenome phylogenetics: the impact of using single regions and partitioning schemes on topology, substitution rate and divergence time estimation. PLoS One. 2011;6, e27138.

4. Vilstrup J, Ho S, Foote A, Morin P, Kreb D, Krutzen M, et al. Mitogenomic phylogenetic analyses of the Delphinidae with an emphasis on the Globicephalinae. BMC Evol Biol. 2011;11:65.

5. Weisrock DW. Concordance analysis in mitogenomic phylogenetics. Mol Phylogenet Evol. 2012;65:194-202.

6. Osca D, Templado J, Zardoya R. The mitochondrial genome of Ifremeria nautilei and the phylogenetic position of the enigmatic deep-sea Abyssochrysoidea (Mollusca: Gastropoda). Gene. 2014;547:257-66.

7. van Oppen MJH, Catmull J, McDonald BJ, Hislop NR, Hagerman PJ, Miller DJ. The mitochondrial genome of Acropora tenuis (Cnidaria; Scleractinia) contains a large group I intron and a candidate control region. J Mol Evol. 2002;55:1-13.

8. Chen IP, Tang C-Y, Chiou C-Y, Hsu J-H, Wei N, Wallace C, et al. Comparative analyses of coding and noncoding DNA regions indicate that Acropora (Anthozoa: Scleractinia) possesses a similar evolutionary tempo of nuclear vs. mitochondrial genomes as in plants. Mar Biotechnol. 2009;11:141-52.

9. Shearer T, van Oppen M, Romano S, Wörheide G. Slow mitochondrial DNA sequence evolution in the Anthozoa (Cnidaria). Mol Ecol. 2002;11:2475-87.

10. Hellberg M. No variation and low synonymous substitution rates in coral mtDNA despite high nuclear variation. BMC Evol Biol. 2006;6:24.

11. Watanabe T, Nishida M, Watanabe K, Wewengkang D, Hidaka M. Polymorphism in nucleotide sequence of mitochondrial intergenic region in scleractinian coral (Galaxea fascicularis). Mar Biotechnol. 2005;7:33-9.

12. Chen C, Dai C-F, Plathong S, Chiou C-Y, Chen C. The complete mitochondrial genomes of needle corals, Seriatopora spp. (Scleractinia: Pocilloporidae): an idiosyncratic atp8, duplicated trnW gene, and hypervariable regions used to determine species phylogenies and recently diverged populations. Mol Phylogenet Evol. 2008;46:19-33.

13. Fukami $\mathrm{H}$, Knowlton N. Analysis of complete mitochondrial DNA sequences of three members of the Montastraea annularis coral species complex (Cnidaria, Anthozoa, Scleractinia). Coral Reefs. 2005;24:410-7.

14. Flot J-F, Tillier S. The mitochondrial genome of Pocillopora (Cnidaria: Scleractinia) contains two variable regions: the putative D-loop and a novel ORF of unknown function. Gene. 2007;401:80-7.

15. Emblem A, Karlsen B, Evertsen J, Johansen S. Mitogenome rearrangement in the cold-water scleractinian coral Lophelia pertusa (Cnidaria, Anthozoa) involves a long-term evolving group I intron. Mol Phylogenet Evol. 2011;61:495-503.

16. Lin M-F, Luzon KS, Licuanan W, Ablan-Lagman MC, Chen C. Seventy-four universal primers for characterizing the complete mitochondrial genomes of scleractinian corals (Cnidaria; Anthozoa). Zool Stud. 2011;50:513-24. 
17. Lin M-F, Kitahara MV, Tachikawa H, Fukami H, Miller DJ, Chen CA. Novel organization of the mitochondrial genome in the deep-sea coral, Madrepora oculata (Hexacorallia, Scleractinia, Oculinidae) and its taxonomic implications. Mol Phylogenet Evol. 2012;65:323-8.

18. Lin M-F, Kitahara MV, Luo H, Tracey D, Geller J, Fukami H, et al. Mitochondrial Genome Rearrangements in the Scleractinia/Corallimorpharia Complex: Implications for Coral Phylogeny. Genome Biol Evol. 2014;6:1086-95.

19. Kitahara MV, Lin M-F, Forêt S, Huttley G, Miller DJ, Chen CA. The "naked coral" hypothesis revisited-evidence for and against scleractinian monophyly. PLoS One. 2014;9, se94774.

20. Zibrowius H. Les scléractiniaires de la Méditerranée et de l'Atlantique nordoriental. Mém Inst Océanogr Monaco. 1980;11:284. 107 pl.

21. Cairns SD. Antarctic and subantarctic Scleractinia. Antarct Res Ser. 1982;34:1-74.

22. Roberts JM, Wheeler A, Freiwald A, Cairns S. Cold-water corals: the biology and geology of deep-sea coral habitats. Cambridge, UK: Cambridge University Press. 2009, 368 pp.

23. Le Goff-Vitry MC, Rogers AD, Baglow D. A deep-sea slant on the molecular phylogeny of the Scleractinia. Mol Phylogenet Evol. 2004;30(1):167-77.

24. Addamo AM, Reimer JD, Taviani M, Freiwald A, Machordom A. Desmophyllum dianthus (Esper, 1794) in the scleractinian phylogeny and its intraspecific diversity. PLoS One. 2012;7, e50215.

25. Stolarski J, Kitahara VM, Miller D, Cairns SD, Mazur M, Meibom A. The ancient evolutionary origins of Scleractinia revealed by azooxanthellate corals. BMC Evol Biol. 2011;11:316.

26. Stolarski J. Origin and phylogeny of Guyniidae (Scleractinia) in the light of microstructural data. Lethaia. 2000;33(1):13-38.

27. Cairns SD. Scleractinia of the temperate north pacific. Smithson Contrib Zool. 1994:557:150

28. Vertino A. Sclerattiniari plio-pleistocenici e attuali del Mediterraneo (sistematica, biostratinomia e paleoecologia). Unpublished PhD thesis. Italy: University of Messina; 2003. p. 306.

29. Beuck L, Vertino A, Stepina E, Karolczak M, Pfannkuche O. Skeletal response of Lophelia pertusa (Scleractinia) to bioeroding sponge infestation visualised with micro-computed tomography. Facies. 2007;53:157-76.

30. Addamo AM, Martínez-Baraldés I, Vertino A, López-González PJ, Taviani M, Machordom A. Morphological polymorphism of Desmophyllum dianthus over a wide ecological and biogeographic range: stability in deep habitats? Zool Anz. 2015:259:113-30.

31. Mortensen PB, Hovland T, Fosså JH, Furevik DM. Distribution, abundance and size of Lophelia pertusa coral reefs in mid-Norway in relation to seabed characteristics. J Mar Biol Assoc U K. 2001;81(4):581-97.

32. Rogers A. The biology of Lophelia pertusa (Linnaeus 1758) and other deep-water reef-forming corals and impacts from human activities. Int Rev Hydrobiol. 1999:84:315-406.

33. Freiwald A, Beuck $L$, Rüggerberg A, Taviani M, Hebbeln D. RN Meteor cruise M70-1 participants. The white coral community in the central Mediterranean Sea revealed by ROV surveys. Oceanogr. 2009:22(1):58-74.

34. Vertino A, Spezzaferri S, Rueggeberg A, Stalder C, Wheeler A, and the Eurofleets CWC-Moira cruise scientific party. An overview on cold-water coral ecosystems and facies. In: Spezzaferri S, Rueggeberg A, Stalder C, editors. Atlas of benthic foraminifera from cold-water coral reefs. J Foraminiferal Res, Special Issue. 2015;44:12-19.

35. Rosso A, Vertino A, Di Geronimo I, Sanfilippo R, Sciuto F, Di Geronimo $\mathrm{R}$, et al. Hard-and soft-bottom thanatofacies from the Santa Maria di Leuca deep-water coral province, Mediterranean. Deep-Sea Res PT II. 2010;57(5):360-79.

36. Vertino A, Savini A, Rosso A, Di Geronimo I, Mastrototaro F, Sanfilippo R. Benthic habitat characterization and distribution from two representative sites of the deep-water SML coral province (Mediterranean). Deep-Sea Res PT II. 2010;57(5-6):380-96.

37. Taviani $M$, Colantoni P. Paléobiocoenoses profondes à scléractiniaires sur l'escarpement de Malte-Syracuse (Mer Méditerranée): leur structure, leur âge et leur signification. Oil Gas Sci Technol. 1984;39:547-59.

38. Freiwald A, Beuck L, Rüggerberg A, Taviani M, Hellben D, ND RN Meteor Cruise M70-1 Participants. White coral community. Oceanography. 2009;22(1):58-74

39. Taviani M, Vertino A, López Correa M, Savini A, De Mol B, Remia A, et al. Pleistocene to recent deep-water corals and coral facies in the eastern Mediterranean. Facies. 2011;57(4):579-603.

40. Försterra G, Häussermann V. First report on large scleractinian (Cnidaria: Anthozoa) accumulations in cold-temperate shallow water of south Chilean fjords. Zool Verhandel. 2003;345:117-28.
41. Cairns SD, Häussermann V, Försterra G. A review of the Scleractinia (Cnidaria: Anthozoa) of Chile, with the description of two new species. Zootaxa. 2005;1018:15-46.

42. Rapp H, Sneli J. Lophelia pertusa - myths and reality. In: Abstracts of the 2nd Nordic Marine Science Meeting, Hirtshals, Denmark 2nd-4th March 1999.

43. Fosså JH, Mortensen PB, Furevik DM. The deep-water coral Lophelia pertusa in Norwegian waters: distribution and fishery impacts. Hydrobiologia. 2002;471:1-12

44. Morrison C, Johnson R, King T, Ross S, Nizinski M. Molecular assessment of deep-sea scleractinian coral biodiversity and population structure of Lophelia pertusa in the Gulf of Mexico. In: Sulak JK, Randall MT, Luke KE, Norem AD, Miller JM, editors. Characterization of northern Gulf of Mexico deepwater hard bottom communities with emphasis on Lophelia coral_L Lophelia reef megafaunal community structure, biotopes, genetics, microbial ecology, and geology. New Orleans, LA, USA: USGS Open-File Report; 2008. p. 4.1-4.70.

45. Morrison C, Eackles M, Johnson R, King T. Characterization of 13 microsatellite loci for the deep-sea coral, Lophelia pertusa (Linnaeus 1758), from the western north Atlantic ocean and gulf of Mexico. Mol Ecol Resour. 2008;8:1037-9.

46. Arrigoni $R$, Vacherie B, Benzoni F, Barbe V. The complete mitochondrial genome of Acanthastrea maxima (Cnidaria, Scleractinia, Lobophylliidae). Mitochondr. DNA. 2014;27(2):927-8.

47. Addamo AM, García Jiménez R, Taviani M, Machordom A. Development of microsatellite markers in the deep-sea cup coral Desmophyllum dianthus and cross-species amplifications in the Scleractinia order. J Hered. 2015;106(3):322-30.

48. Cairns SD. The deep-water Scleractinia of the Caribbean Sea and adjacent waters. Stud Fauna Curaçao Caribbean Is. 1979;57(180):341.

49. Stolarski J. Ontogenetic development of the thecal structures in Caryophylliine scleractinian corals. Acta Palaeontol Pol. 1995:40:19-44.

50. Flot J-F, Dahl M, André C. Lophelia pertusa corals from the lonian and Barents seas share identical nuclear ITS2 and near-identical mitochondrial genome sequences. BMC Res Notes. 2013;6:144

51. Nei M, Kumar S. Molecular Evolution and Phylogenetics. New York, USA: Oxford University Press. 2000, 333pp.

52. van Oppen MJH, McDonald BJ, Willis B, Miller DJ. The evolutionary history of the coral genus Acropora (Scleractinia, Cnidaria) based on a mitochondrial and a nuclear marker: reticulation, incomplete lineage sorting, or morphological convergence? Mol Biol Evol. 2001;18:1315-29.

53. Huang D. Threatened reef corals of the world. PLoS One. 2012:7(3), e34459.

54. Chatrou LW, Escribano MP, Vireul MA, Maas JW, Richardson JE, Hormaza Jl. Flanking regions of monomorphic microsatellite loci provide a new source of data for plant species-level phylogenetics. Mol Phylogenet Evol. 2009;53(3):726-33.

55. Primmer $\mathrm{CR}$, Møller AP, Ellegren $\mathrm{H}$. A wide-range survey of cross-species microsatellites amplification in birds. Mol Ecol. 2009;5(3):365-78.

56. Zardoya R, Vollmer DM, Craddock C, Streelman JT, Karl S, Meyer A. Evolutionary conservation of microsatellite flanking regions and their use in resolving the phylogeny of cichlid fishes (Pisces: Perciformes). P Roy Soc Lond B Biol Sci . 1996;263(1376):1589-98.

57. Estoup A, Tailliez C, Cornuet JM, Solignac M. Size homoplasy and mutational processes of interrupted microsatellites in two bee species, Apis mellifera and Bombus terrestris (Apidae). Mol Biol Evol. 1995;12:1074-84.

58. Le Goff MC, Rogers AD. Characterization of 10 microsatellite loci for the deep-sea coral Lophelia pertusa (Linnaeus 1758). Mol Ecol Notes. 2002:2: 164-6.

59. Kornobis E, Cabellos L, Aguilar F, Frías-López C, Rozas J, Marco J, et al. TRUFA: a USer-friendly Web server for de novo RNA-seq analysis using cluster computing. Evol Bioinform Online. 2015;11:97-104.

60. Zuffardi-Comerci R. Corallari-zoantari fossili del Miocene della "collina di Torino". Palaeontogr Ital. 1932;33:85-132.

61. Vertino A, Stolarski J, Bosellini FR, Taviani M. Mediterranean corals through time: from Miocene to Present. In: Goffredo S, Dubinsky Z, editors. The Mediterranean Sea: Its history and present challenges, chapter: 14. New York, London: Springer Dordrecht Heidelberg; 2014. p. 257-74

62. Budd AF, Romano SL, Smith ND, Barbeitos MS. Rethinking the phylogeny of scleractinian corals: a review of morphological and molecular data. Integr Comp Biol. 2010;50(3):411-27.

63. Cairns SD. A revision of the shallow-water azooxanthellate Scleractinia of the western Atlantic. Stud Fauna Curacao Caribbean Isl. 2000;75:1-240.

64. Käsbauer T, Towb P, Alexandrova O, David CN, Dall'Armi E, Staudigl A, et al. The notch signaling pathway in the cnidarian. Hydra Dev Biol. 2007;303:376-90. 
65. Marlow H, Roettinger E, Boekhout M, Martindale MQ. Functional roles of notch signaling in the cnidarian Nematostella vectensis. Dev Biol. 2012;362:295-308.

66. Hemond EM, Kaluziak ST, Vollmer SV. The genetics of colony form and function in Caribbean Acropora corals. BMC Genomics. 2014;15:1133.

67. Barbeitos MS, Romano SL, Lasker HR. Repeated loss of coloniality and symbiosis in scleractinian corals. Proc Natl Acad Sci USA. 2010;107(26):11877-82.

68. Ocaña O, Brito A. Balanopsammia wirtzi, a new genus and species of coral (Anthozoa: Scleractinia: Dendrophylliidae) from the cape Verde islands a comparative study with the Mediterranean Cladopsammia rolandi. Rev Acad Canar Cienc. 2013;25(1):87-104

69. Wells JW. Scleractinia. In: Moore RC, editor. Treatise on invertebrate paleontology. Kansas: Geological Society of America and University of Kansas Press; 1956. p. 328-444

70. Veron JEN. Corals of the world. 1-3rd ed. Townsville: Australian Institute of Marine Science; 2000. p. 1382.

71. Cairns SD, Kitahara MV. An illustrated key to the genera and subgenera of the recent azooxanthellate Scleractinia (Cnidaria, Anthozoa), with an attached glossary. ZooKeys. 2012;227:1-47.

72. Benzoni F, Stefani F, Stolarski J, Pichon M, Mitta G, Galli P. Debating phylogenetic relationships of the scleractinian Psammocora, molecular and morphological evidences. Contrib Zool. 2007;76(1):35-54.

73. Budd AF, Stolarski J. Corallite wall and septal microstructure in scleractinian reef corals: comparison of molecular clades within the family Faviidae. J Morphol. 2011;272:66-88

74. Schmidt-Roach S, Miller KJ, Lundgren P, Andreakis N. With eyes wide open: a revision of species within and closely related to the Pocillopora damicornis species complex (Scleractinia; Pocilloporidae) using morphology and genetics. Zool J Linn Soc Lond. 2014;170:1-33.

75. Spezzaferri S, Vertino A, the E-CWC Moira cruise scientific party. Cold-water coral ecosystems from the Moira Mounds (NE Atlantic): affinities and differences with modern and Pleistocene Mediterranean counterparts. RV Belgica, Cruise No. 2012/16, EUROFLEETS—CWC Moira Cruise Unpublished Report. 2012, 30 pp.

76. De Mol L, Hilário A, Larmagnat S, Henriet JP. Cruise report Belgica 09/14b, Belgica GENESIS, Leg 2 "Pen duick". Gulf of Cadiz, Ghent: Renard Centre of Marine Geology, Ghent University; 2009. 53 pp.

77. van Rooij D, Hebbeln D, Comas M, Vandorpe T, Delivet S. MD194 shipboard scientists. EuroFLEETS cruise summary report "MD194 GATEWAY", Cádiz (ES)Lisbon (PT). Belgium: Ghent University; 2013. p. 214. 10-21 June 2013.

78. D'Onghia G, Savini A, the MAGIC/CoralFISH shipboard party. Cruise unpublished report, Northern Ionian Sea (Santa Maria di Leuca CWC Province). 2010, 32 pp.

79. Rozen S, Skaletsky H. Primer3 on the WWW for general users and for biologist programmers. Methods Mol Biol. 2000;132:365-86.

80. Lowe T, Eddy S. TRNAscan-SE: a program for improved detection of transfer RNA genes in genomic sequence. Nucleic Acids Res. 1997;25:955-64.

81. Wyman SK, Jansen RK, Boore JL. Automatic annotation of organellar genomes with DOGMA. Bioinformatics. 2004;20:3252-5.

82. Bernt $M$, Donath $A$, Jühling $F$, Externbrink $F$, Florentz $C$, Fritzsch $G$, et al. MITOS: improved de novo metazoan mitochondrial genome annotation. Mol Phylogenet Evol. 2013;69:313-9.

83. Zhang Z, Li J, Zhao X-Q, Wang J, Wong G-S, Yu J. KaKs_calculator: calculating $\mathrm{Ka}$ and $\mathrm{Ks}$ through model selection and model averaging. Genomics Proteomics Bioinformatics. 2006;4:259-63.

84. Larkin MA, Blackshields G, Brown NP, Chenna R, McGettigan PA, McWilliam H, et al. Clustal W and Clustal X version 2.0. Bioinformatics. 2007:23:2947-8.

85. Rambaut A. Se-Al. Alignment editor. Version 2.0a11. Oxford: University of Oxford; 2002

86. Swofford DL. PAUP*: phylogeny analysis using parsimony (*and other methods). Sunderland, Massachusetts: Sinauer Associated Inc; 2002.

87. Miller K, Gunasekera R. Are seamounts isolated islands or stepping stones for oceanic dispersal? A comparison of genetic connectivity and population structure in two deep sea corals. (submitted)

88. Stolarski J. 3-dimensional micro- and nanostructural characteristics of the scleractinian corals skeleton: a biocalcification proxy. Acta Palaeontol Pol. 2003:48:497-530

\section{Submit your next manuscript to BioMed Central and we will help you at every step:}

- We accept pre-submission inquiries

- Our selector tool helps you to find the most relevant journal

- We provide round the clock customer support

- Convenient online submission

- Thorough peer review

- Inclusion in PubMed and all major indexing services

- Maximum visibility for your research

Submit your manuscript at www.biomedcentral.com/submit

) Biomed Central 